\title{
Hitting the target: where do molecularly targeted therapies fit in the treatment scheduling of neuroendocrine tumours?
}

\author{
Anna Karpathakis ${ }^{1,2}$, Martyn Caplin ${ }^{3}$ and Christina Thirlwell ${ }^{1,2}$ \\ ${ }^{1}$ University College London Cancer Institute, Paul O'Gorman Building, Huntley Street, London WC1E 6BT, UK \\ ${ }^{2}$ Department of Oncology and ${ }^{3}$ Neuroendocrine Tumour Unit, Department of Gastroenterology, Royal Free Hospital, \\ London NW3 2QG, UK \\ (Correspondence should be addressed to C Thirlwell at University College London Cancer Institute; \\ Email: christina.thirlwell@ucl.ac.uk)
}

\begin{abstract}
Neuroendocrine tumours (NETs) are a rare and heterogeneous group of tumours whose incidence is increasing and their prevalence is now greater than that of any other upper gastrointestinal tumour. Diagnosis can be challenging, and up to $25 \%$ of patients present with metastatic disease. Following the recent FDA approval of two new molecularly targeted therapies for the treatment of advanced pancreatic NETs (pNETs), the first in 25 years, we review all systemic therapies and suggest where these newer targeted therapies fit in the treatment schedule for these challenging tumours. Clinical trial data relating to the routine use of sunitinib and everolimus in low-intermediate-grade pNETs are summarised alongside newer molecularly targeted agents undergoing clinical assessment in NETs. We particularly focus on the challenge of optimal scheduling of molecularly targeted treatments around existing systemic and localised treatment such as chemotherapy or radiotargeted therapy. We also discuss application of current evidence to subgroups of patients who have not so far been directly addressed such as those with poorer performance status or patients receiving radical surgery who may benefit from adjuvant treatment.
\end{abstract}

Endocrine-Related Cancer (2012) 19 R73-R92

\section{Introduction}

Neuroendocrine tumours (NETs) comprise a genetically and clinically heterogeneous group of tumours. In order to maximise the best clinical outcome for patients, they should be managed by a multidisciplinary group of experienced clinicians including oncologists, gastroenterologists, endocrinologists, nuclear medicine physicians and surgeons. NETs can present with a variety of constitutional symptoms, and diagnosis can be delayed for up to 5 years on average, particularly if non-syndromic. Prognostication and clinical outcomes are currently based on the primary site of the NET and the histological grade of the tumour. Radical surgery for localised disease is the only known curative treatment. Systemic therapies include somatostatin analogues (SSAs), chemotherapy, peptide receptor radionuclide therapy (PRRT), interferon- $\alpha$ (IFN $\alpha$ ) and most recently the molecularly targeted agents sunitinib and everolimus. It is clear that marked differences in molecular pathogenesis are evident between NETs of different sites of origin. This has been observed in clinical trials of NETs in recent years where marked differences in response to molecularly targeted therapy had been observed in pancreatic, bronchial and intestinal NETs. It is now widely accepted that pathological subgroups of NET (depending on site of origin) should be assessed while developing clinical trials (Kulke et al. 2011).

In this review, we summarise the current systemic treatment options for NETs of bronchial, pancreatic and intestinal origin and discuss recent advances in the elucidation of the biological pathways involved in the development of pancreatic NETs (pNETs), focusing on the use and suggested scheduling of sunitinib and everolimus. 


\section{Pathogenesis}

NETs are 'rare' tumours with a relatively low incidence (5/100 000 population), and high prevalence, higher than any other upper gastrointestinal cancer (Yao et al. $2008 a, b)$, both the incidence and prevalence are rising. Over $90 \%$ of NETs are sporadic, the remaining $\sim 10 \%$ are associated with familial syndromes including multiple endocrine neoplasia 1 (MEN1) syndrome, von Hippel-Lindau (VHL), tuberous sclerosis (TSC) and neurofibromatosis (NF1) (Calender 2006). Current pathological staging and grading differs between Europe and the USA; however, both the classification systems are centred around the primary site of the tumour and histological grade. In Europe, the Ki-67 proliferative index is used to differentiate tumours of low $(<2 \%)$, intermediate $(2-20 \%)$ and high $(>20 \%)$ grades, whereas in the USA, tumours are graded as 'well' and 'poorly' differentiated where 'well' equates to low-intermediate-grade and 'poorly' equates to highgrade tumours. The current staging systems are reviewed by Kulke et al. (2011). The most common familial NET syndromes are summarised below.

\section{Familial NET syndromes}

MEN1 syndrome is characterised by parathyroid hyperplasia/adenoma, pancreatic endocrine tumours (25-80\% mostly non-functioning, gastrinomas or insulinomas), pituitary tumours and adrenocortical adenomas (Brandi et al. 2001, Akerstrom et al. 2005). MEN1 is the result of germline inactivation of the tumour suppressor MEN1 gene (localised to 11q13) and subsequent loss of the wild-type allele (Marx 2005).

VHL syndrome is caused by an autosomal dominantly inherited germline mutation in the VHL tumour suppressor gene (at locus 3p25.5), the second wild-type allele is lost somatically. Pancreatic non-functioning NETs develop in $12-17 \%$ of patients with VHL (Hammel et al. 2000, Blansfield et al. 2007). The syndrome leads to the development of central nervous system and retinal haemangiomas, renal carcinomas and pheochromocytomas and pNETs (Lott et al. 2002).

NF1 is an autosomal dominant disorder characterised by cafe au lait spots, neurofibromas, optic gliomas, iris hamartomas and pancreatic somatostatinomas $(6 \%)$. This syndrome is caused by mutation of the NF1 tumour suppressor gene (chromosome 17q11.2). It has been shown that $N F 1$ acts as a negative regulator of mammalian target of rapamycin (mTOR; Johannessen et al. 2005), suggesting that NF1-related NETs might be particularly susceptible to mTOR pathway-targeted therapies.
TSC is an autosomal dominant disease characterised by hamartomas and astrocytomas and well-differentiated tumours in brain, heart, skin, kidney, lung and pancreas (NET $<5 \%)$, and it is often associated with epilepsy and learning difficulties. TSC is caused by mutation of TSC1 (hamartin, chromosome 9q34) or TSC2 (tuberin, chromosome 16p13.3). The hamartin-tuberin complex normally inactivates the protein Ras homologue enriched in brain (Rheb) that functions to activate the mTOR signalling pathway (Huang \& Manning 2008). The TSC protein complex therefore acts as an intrinsic suppressor of mTOR signalling, and when mutated leads to constitutive activation, again suggesting susceptibility to mTOR inhibition therapy in these patients.

\section{Signalling pathways involved in NET development}

Vascular endothelial growth factor (VEGF) pathway activation plays a major role in the development of several solid cancers. Activation of the VEGF receptor (VEGFR) family triggers a signalling cascade resulting in increased endothelial cell survival, mitogenesis, migration and vascular permeability. Associated pathways include induction of the phosphoinositide 3-kinase/AKT (PI3K/AKT) pathway, metalloproteinases, activation of mitogen-activated protein kinases and upregulation of integrin expression (Hicklin \& Ellis 2005). VEGF is physiologically upregulated by hypoxia inducible factor (HIF1- $\alpha$ (HIF1A)), which is usually degraded in the presence of VHL. In the absence or mutation of $V H L$, levels of HIF- $1 \alpha$ rise leading to the transcription of over 100 hypoxia-related genes involving angiogenesis, glucose metabolism, erythropoietin production, cellular proliferation, tumour invasion/metastasis and p53 (TP53)-mediated apoptosis (Semenza 2003). Bi-allelic inactivation of $V H L$ leads to the development of pNET development in up to $12 \%$ of cases (Hammel et al. 2000). There is increasing evidence to suggest that disruption of the VHL pathway and subsequent HIF activation occurs in sporadic pNETs (Couvelard et al. 2005, 2008, Schmitt et al. 2009).

Dysregulation of the mTOR pathway is known to be involved in the pathogenesis of up to $80 \%$ of human cancers (Watanabe et al. 2011). It forms two complexes (mTORC1 and 2) and integrates signals from multiple sources (including glucose, growth factors such as insulin-like growth factor 1 (IGF1) and hormones such as leptin) by signalling through the PI3K/AKT system (Goldstein \& Meyer 2011). Through phosphorylation of a variety of kinases and 
proteins, mTOR regulates survival, metabolism, proliferation and angiogenesis (the latter through activation of HIF). Inhibition of this pathway by everolimus and similar compounds is therefore an attractive anti-cancer mechanism. Figure 1 shows an overview of intracellular signalling pathways.

Following the recent exome sequencing of sporadic pNETs, significant advances have been made in determining the biological pathways underlying the pathogenesis of pNETs (Jiao et al. 2011). This study on 68 (ten discovery and 58 validation) primary and metastatic sporadic pNETs identified mutations in ATRX/DAXX and menin in 43 and $44 \%$ of tumours respectively. All these genes are involved in chromatin modelling, and the functional implications of these mutations are yet to be elucidated. Patients harbouring these mutations were found to have a significantly improved overall survival. Fourteen per cent of pNETs were also found to harbour mutations in genes involved in the mTOR pathway including phosphatase and tensin homologue (PTEN), TSC2 and PI3K catalytic alpha polypeptide (PIK3CA; Jiao et al. 2011). A previous study found that $85 \%$ of pNETs had reduced expression of TSC2 or PTEN or both, these tumours were more aggressive and found to have a higher $\mathrm{Ki}-67$ proliferation index, shorter time to progression and overall survival (Missiaglia et al. 2010). These two studies suggest that there is an identifiable cohort of patients who would gain particular benefit from treatment targeted to inhibiting the mTOR pathway; however, these potential novel biomarkers require further validation in larger clinical cohorts.

It is widely accepted that in order to fully understand the pathogenesis and clinically stratify this heterogeneous group of tumours, comprehensive genomic analyses are required and are currently ongoing.

The rationale and preclinical data supporting the use of VEGF and mTOR molecularly targeted therapies are discussed in the Molecularly Targeted Therapy section of this review.

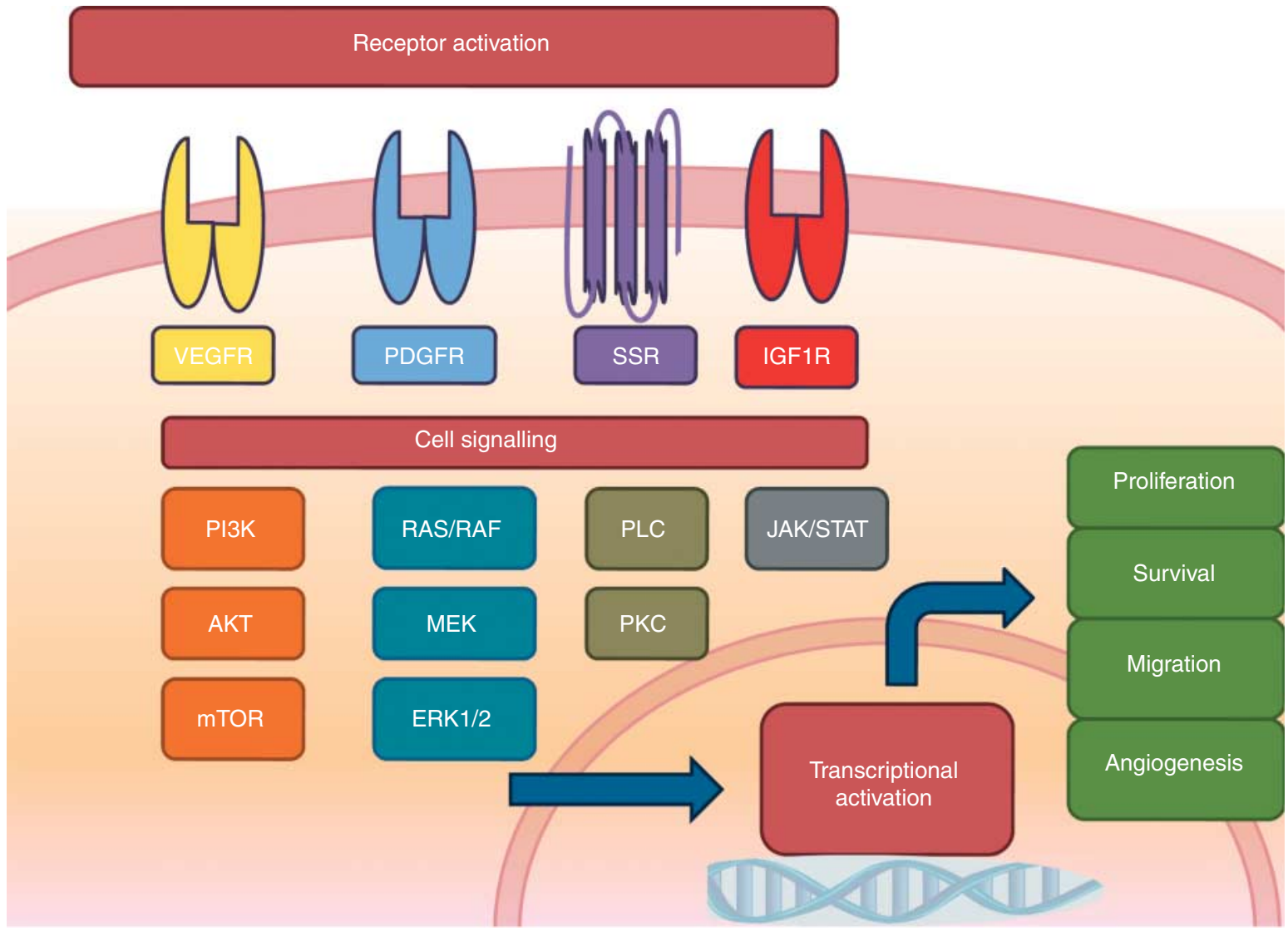

Figure 1 Intracellular signalling pathways in neuroendocrine tumours showing the PI3K/AKT/mTOR; RAS/RAF/MEK/ERK; PLC/PKC and JAK/STAT pathways. Adapted from Raymond et al. (2011a,b). VEGFR, vascular endothelial growth factor receptor; PDGFR, platelet derived growth factor receptor; SSR, somatostatin receptor; IGF1R, insulin like growth factor 1 receptor; PI3K, phosphoinositide 3-kinase; RAS, rat sarcoma protein; PLC, phospholipase C; PKC, protein kinase C; JAK/STAT, Janus kinase signal transducer and activator of transcription. 


\section{Review of systemic therapies and current guidelines}

Due to the rarity of NETs, there is a lack of large-scale randomised controlled trials (RCTs); therefore, much of our understanding in NET management is based on non-randomised phase II clinical studies that have not compared the treatment under investigation against any best supportive or gold standard therapy. In light of this, treatment protocols and sequencing of therapies vary from centre to centre, although national and international guidelines have been published. An overview of available treatment options for gastroenteropancreatic (GEP) NETs is shown in Fig. 2.

There have been four RCTs of chemotherapy, two in pNETs and two in gastrointestinal NETs, three for IFN and three studying molecularly targeted therapies (summarised in Table 1). No RCTs have been performed in the field of PRRT. The first novel therapies to be licensed for NET for 25 years were introduced in 2011: sunitinib and everolimus. Both are molecularly targeted agents inhibiting well-described cancer signalling pathways (with everolimus targeting mTOR and sunitinib VEGF). This represents significant progress for NET systemic therapy not only in improved clinical outcome for patients but also through demonstrating the feasibility of performing large-scale international randomised controlled phase III trials in rare cancers.

The most recently published European Neuroendocrine Tumour Society (ENETS) guidelines discuss the use of molecularly targeted treatment in the second- or third-line setting for well-differentiated non-functioning pancreatic tumours, and everolimus for gastrointestinal tumours (Falconi et al. 2011, Pavel et al. 2011a,b). The most recent North American NET Society (NANETs) guidelines only briefly discuss targeted therapy and provide no guidance on usage (Kulke et al. 2010). ESMO guidelines on GEP NETs provide no specific guidance on the subject of molecularly targeted therapy, reflecting the rapid progress and new developments over the last year (Oberg et al. 2010a,b). The United Kingdom and Ireland NET Society (UKINETS) group have

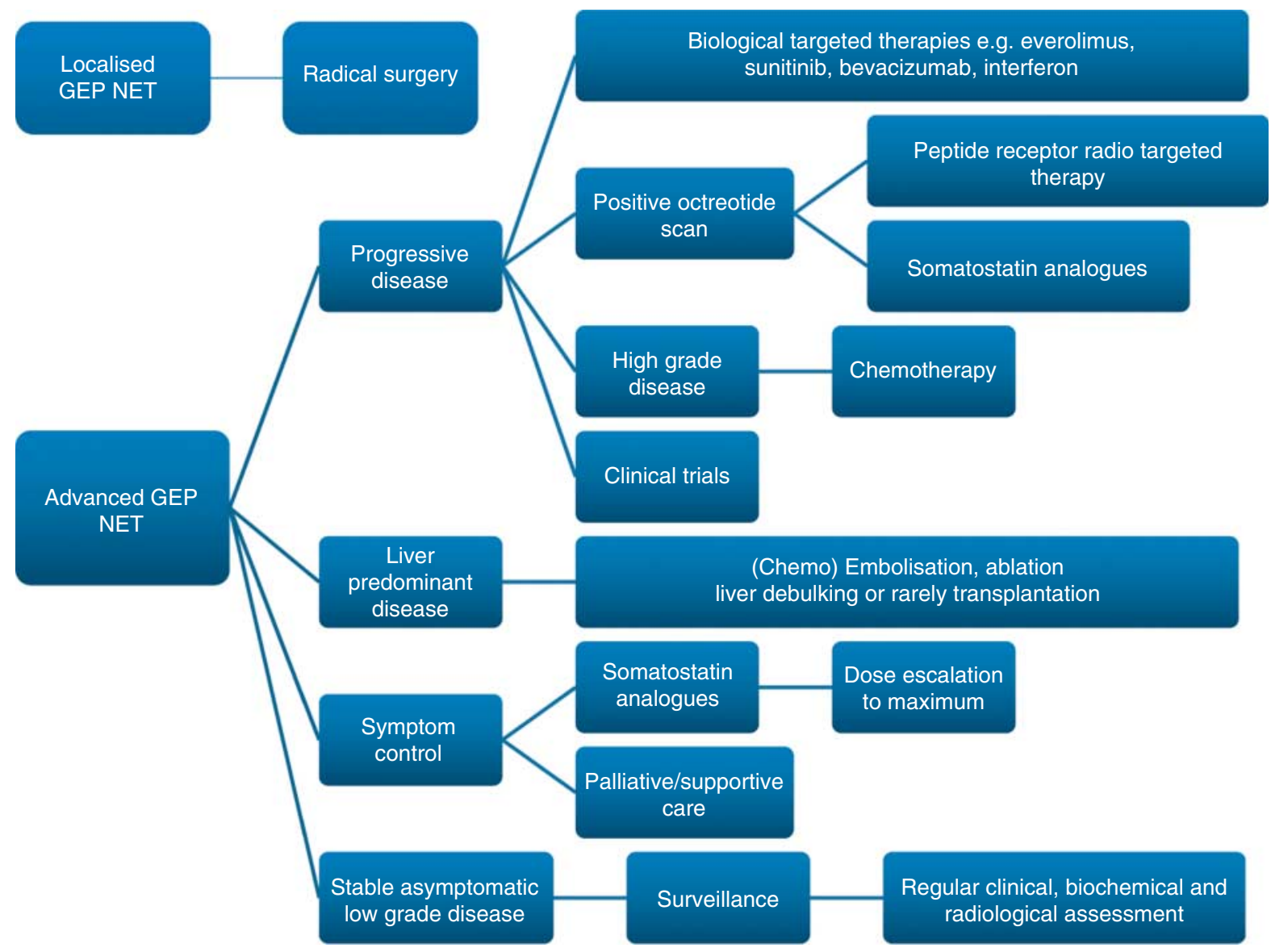

Figure 2 Flow diagram of therapies for localised and advanced gastroenteropancreatic neuroendocrine tumours. 
Table 1 Randomised controlled trials in NETs

\begin{tabular}{|c|c|c|c|}
\hline Reference & Trial summary & $\begin{array}{l}\text { Number of } \\
\text { participants }\end{array}$ & Outcome \\
\hline Moertel et al. (1980) & $\begin{array}{l}\text { Chemotherapy } \\
\text { STZ vs F-STZ in islet cell }\end{array}$ & 84 & $\begin{array}{l}\text { ORR } 63 \text { vs } 36 \% \\
\text { CR } 33 \text { vs } 12 \%\end{array}$ \\
\hline Moertel et al. (1992) & $\begin{array}{l}\text { Chemotherapy } \\
\text { STZ-dox vs STZ-F vs chlorozotocin in islet cell }\end{array}$ & 105 & $\begin{array}{l}\text { ORR } 69 \text { vs } 45 \% \\
\text { OS } 2.2 \text { vs } 1.4 \text { years (STZ-dox vs STZ-F) }\end{array}$ \\
\hline Engstrom et al. (1984) & $\begin{array}{l}\text { Chemotherapy } \\
\text { STZ-F vs dox in carcinoid }\end{array}$ & 172 & $\begin{array}{l}\text { ORR } 22 \text { vs } 21 \% \\
\text { OS } 64 \text { vs } 48 \text { weeks }\end{array}$ \\
\hline Sun et al. (2005) & $\begin{array}{l}\text { Chemotherapy } \\
\text { F-Dox vs F-STZ vs DTIC in carcinoid }\end{array}$ & 249 & $\begin{array}{l}\text { ORR } 15.9 \text { vs } 16 \% \\
\text { OS } 24.3 \text { vs } 15.7 \mathrm{~m} \text { (F-STZ vs F-Dox) }\end{array}$ \\
\hline Kolby et al. (2003) & $\begin{array}{l}\text { IFN } \\
\text { SSA + IFN vs SSA in midgut carcinoid }\end{array}$ & 68 & 5 years OS: 57 vs $37 \%(P=0.13)$ \\
\hline Faiss et al. (2003) & $\begin{array}{l}\text { IFN } \\
\text { SSA vs IFN vs combination in GEP NET }\end{array}$ & 83 & Comparable antiproliferative effects \\
\hline Arnold et al. (2005) & $\begin{array}{l}\text { IFN } \\
\text { Octreotide vs Octreotide+IFN in GEP NET }\end{array}$ & 109 & $\begin{array}{l}\text { Combination therapy not superior to } \\
\text { monotherapy for PFS or OS }\end{array}$ \\
\hline Raymond et al. $(2011 a, b)$ & $\begin{array}{l}\text { Targeted } \\
\text { Sunitinib vs BSC in pNET }\end{array}$ & 171 & $\begin{array}{l}\text { PFS } 11.4 \text { vs } 5.5 \mathrm{~m} \\
\text { ORR } 9.3 \text { vs } 0 \%\end{array}$ \\
\hline Yao et al. (2011) & $\begin{array}{l}\text { Targeted } \\
\text { Everolimus vs placebo in advanced low/ } \\
\text { intermediate grade pNET }\end{array}$ & 410 & PFS 11.0 vs $4.6 \mathrm{~m}$ \\
\hline Pavel et al. $(2011 a, b)$ & $\begin{array}{l}\text { Targeted } \\
\text { Everolimus plus SSA vs SSA in NET } \\
\quad \text { associated with carcinoid syndrome }\end{array}$ & 429 & PFS $16.4 \mathrm{~m}$ vs $11.3(P=0.026)$ \\
\hline
\end{tabular}

STZ, streptozocin; F, fluorouracil; dox, doxorubicin; DTIC, dacarbazine; IFN, interferon; SSA, somatostatin analogue; GEP NET, gastroenteropancreatic neuroendocrine tumour; BSC, best supportive care; pNET, pancreatic NET.

published the second most recent guidelines for the management of GEP NETs which includes the use of molecularly targeted therapy (Ramage et al. 2012).

\section{Chemotherapy}

It was first noted in the 1970s and 80 's that streptozocin, doxorubicin and 5-fluorouracil (5-FU) have clinical benefit in NETs (Strosberg et al. $2011 a, b)$. Since then there have been a number of phase II trials which have failed to replicate the initial efficacy of streptozocin and doxorubicin originally reported for these agents $(50 \%$ - streptozocin, $45 \%$ 5-FU/doxorubicin). The original trials used nonradiological parameters for response such as clinical examination for hepatomegaly and serum tumour marker levels rather than standardised radiological criteria such as Response Evaluation Criteria in Solid Tumours (RECIST). Three studies since (using RECIST criteria) have yielded similar results using combination therapy with streptozocin, 5-FU and doxorubicin (Kouvaraki et al. 2004), streptozocin, cisplatin and 5-FU (Turner et al. 2010), streptozocin and doxorubicin (Delaunoit et al. 2004). The partial response (PR) rates for these studies being 39, 38 and $36 \%$ respectively. The observed response rate (RR) varies between 30 and $40 \%$ for combination therapy in the majority of studies, with one recent study reporting a response rate of $70 \%$ (Strosberg et al. 2011a,b). pNETs are more sensitive than non-pNETs to streptozocin based combination chemotherapy, this is supported by in vitro evidence which suggests that streptozocin is preferentially taken up by $\beta$-islet cells in the pancreas (Anderson et al. 1974). High-grade NETs (Ki-67>20\%) have $\sim 50 \%$ response rate to platinum based regimes. Newer chemotherapy agents such as gemcitabine and docetaxel have been trialled in the phase II setting and do not appear promising clinically.

Most recently, temozolomide has been trialled with capecitabine (an oral pro-drug of 5-FU) in the first line treatment of low- and intermediate-grade pNETs. Although non-randomised and retrospective, this trial of only 30 patients found a remarkable response rate of $70 \%$ (Strosberg et al. 2011a,b) with progression-free survival of 18 months and 2 year overall survival of $92 \%$. Previously, this regimen has been used as second-line treatment where streptozocin based therapy had failed in intermediate and high-grade tumours (Isacoff et al. 2006). A phase II trial of temozolomide in combination with thalidomide found a radiological response rate of $25 \%$ $(45 \%$ in pNETs and only $7 \%$ in gastrointestinal tumours; Kulke et al. 2006). 
The choice of chemotherapy regime depends on the grade (based on Ki-67 proliferative index), primary site of the tumour and stage of disease. Other factors such as performance status (PS) and previous treatment schedules require consideration on a case-by-case basis by the multidisciplinary team. Combination chemotherapy with up to three drugs including streptozocin, doxorubicin, 5-FU (or capecitabine), temozolomide, cisplatin and etoposide is commonly used, the exact schedule and dosing varies from centre to centre. The ENETS guidelines for standard of care with systemic chemotherapy have most recently been published in 2011 (Pavel et al. 2011a,b).

\section{Low- to intermediate-grade (well-differentiated) PNETs and gastrointestinal NETs}

pNETs are known to have a higher response rate to streptozocin-based chemotherapy; therefore in treatment of in-operable, metastatic tumours, chemotherapy is recommended following failure of biotherapy. The commonly used combination chemotherapy regimens lead to an expected response rate of between 30 and $40 \%$. Our institute uses a combination of 5-FU, streptozocin and cisplatin given intravenously 3 weekly as an outpatient. This regime is well tolerated, given as an outpatient and unlike regimes containing doxorubicin, patients are not exposed to associated cardiotoxicity and do not experience alopecia. A review of 82 patients treated with this regime found PR and stable disease (SD) in 38 and $51 \%$ of PNET patients and PR and SD of 25 and $50 \%$ of non-pNET patients respectively (Turner et al. 2010).

Gastrointestinal NETs have a lower response rate to chemotherapy, and it is recommended that chemotherapy is used as a second-line therapy where other systemic therapy has failed unless the tumour is of high grade (Ki-67>20\%) or if the tumour is of goblet cell origin. Metastatic goblet cell tumours arise almost exclusively in the appendix, many of the markers they express are the same as colorectal adenocarcinoma; however, the chromosomal changes occurring in these tumours are often the same as ileal NETs. Currently, they are treated with the same chemotherapy agents as colorectal adenocarcinoma - 5-FU and oxaliplatin (FOLFOX), given intravenously 2 weekly. This regimen is also given in the adjuvant setting for patients with stage III disease post-operatively. Recent ENETS Consensus guidelines for goblet cell carcinomas review current standards of care (Pape et al. 2011).

\section{High-grade (poorly differentiated) NETs}

Platinum-based chemotherapy is recommended for high-grade (Ki-67>20\%) tumours. When used in combination with etoposide, a response rate of $\sim 50 \%$ is observed (Eriksson et al. 2009). In highgrade PNETs with multiple metastases, chemotherapy is advised as the first-line therapy. Response to treatment is assessed by RECIST criteria on review of cross-sectional computed tomography (CT) imaging 2-3 months after commencing therapy, tumour markers (where available) and clinical response - in terms of the patient symptoms.

In patients with low-intermediate-grade tumours, it is common to observe a delayed response to treatment on CT imaging 4 months after commencing therapy (Kouvaraki et al. 2004, Turner et al. 2010). Therefore, if SD is present at the first-interval scan, the chemotherapy course should be completed if the patient is able to tolerate the treatment and there are no other complications.

\section{Bronchial NETs}

A small study on single-agent temozolomide reported a clinical benefit rate (response or stabilisation) in $62 \%$ of participating patients with bronchial NET ( $n=13$; Ekeblad et al. 2007). In two cases, neoadjuvant 5-FU/cisplatin/streptozocin chemotherapy has been used successfully to downstage bronchial NET before curative surgery (Srirajaskanthan et al. 2009), other small series reported promising results with doxorubicin-based chemotherapy (Granberg et al. 2001). Prospective randomised trials are required to determine the role of chemotherapy and optimal treatment regimen in these patients. Clinical practice guidelines for bronchial NET have been published by the European Society of Medical Oncology (Oberg et al. 2010a,b).

\section{Immunological modulators}

IFNs have been used in cancer therapy for over 25 years and are known to exert anti-tumoral effects through stimulation of $\mathrm{T}$ cells, induction of cell cycle arrest and inhibition of angiogenesis (Parmar \& Platanias 2005). Interestingly, in NETs, IFNs can upregulate somatostatin receptor expression (Hofland et al. 1999). IFN $\alpha$ is the IFN subtype most studied in NETs both in vitro and clinically. The first clinical study on IFN $\alpha$ in NETs was conducted in 1983 in patients with midgut NETs (Oberg et al. 1983).

To date, however, there have been promising phase II studies, but all the three RCTs published have been 
non-significant when IFN $\alpha$ was trialled concomitantly with SSAs in intestinal NETs. In one such study in which 68 patients were treated with subcutaneous octreotide alone or in combination with 3 million units of IFN $\alpha$ five times per week, the 5-year overall survival was increased in the combination arm (57 vs $37 \%)$ but was not found to be significant $(P=0.13$; Kolby et al. 2003). Objective response rates in two further RCTs were $\sim 7$ and $6 \%$ respectively (Faiss et al. 1996, Arnold et al. 2005). All the three RCTs performed to date were underpowered and no statistically significant overall survival data can be determined. Alongside this, an optimum dosing schedule is yet to be published. Many clinicians chose not to use IFN $\alpha$ due to the difficulties of balancing the sometimes debilitating side effects of fatigue, myalgia and fever; bone marrow suppression and depression with clinical benefit.

In selected cases in centres with previous clinical experience, however, IFN $\alpha$ can lead to symptom control and disease stabilisation of long-term duration up to a number of years.

\section{Somatostatin analogues}

Up to $80 \%$ of GEP NETs express somatostatin receptors ( $\mathrm{SST}_{2}$ and $\mathrm{SST}_{5}$ primarily). SSAs have been used for the treatment of NETs since the 1980s and have a marked effect on improving many of the hormonal symptoms experienced in functioning NETs. Physiologically, somatostatin causes reduced gastrointestinal secretion, inhibition of peristalsis, decreased portal blood flow and down-regulation of the secretion of several intestinal hormones.

Somatostatin binds to five G-protein-coupled somatostatin receptors (SSTR1-5). Initial clinical use of human somatostatin was hindered by its short half-life of $\sim 2 \mathrm{~min}$. The key study that demonstrated a clinical effect of SSAs was published by Kvols et al. (1986); this demonstrated an improvement in flushing and diarrhoea in 22/25 (88\%) patients, with a significant reduction in urinary 5 -hydroxyindoleacetic acid (5-HIAA) in 18/25 (72\%) patients. More recently, long-acting depot synthetic SSAs have been manufactured, which have been used for symptom control including octreotide acetate (Rubin et al. 1999) and lanreotide (Ruszniewski et al. 1996). The PROMID study in 2009 (Rinke et al. 2009) demonstrated improved time to progression and disease control in intestinal NETs with SSA use (TTP $14.3 \mathrm{~m}$ with octreotide LAR vs $6 \mathrm{~m}$ with placebo $P<0.0001$ ). Since then, several trials have confirmed the antisecretory effects of SSAs in functional intestinal NETs as well as VIPoma and glucagonoma (Maton et al. 1989, di Bartolomeo et al. 1996, Rubin et al. 1999, O'Toole et al. 2000). There is also evidence of an antiproliferative effect of SSAs on type I and II gastric carcinoids with reduction in tumour volume and reduced serum gastrin levels demonstrated (Tomassetti et al. 2000, Grozinsky-Glasberg et al. 2008a,b).

The most commonly used long-acting SSAs in clinical use are octreotide LAR (10-30 mg given by deep i.m. injection 3-4 weekly) and lanreotide (60-120 mg given s.c. every 4-6 weeks). Both analogues bind with high avidity to $\mathrm{SST}_{2}$ and $\mathrm{SST}_{5}$. In patients who develop refractory hormonal symptoms, the dose of both these agents can be increased by increasing the frequency of injections to 3 weekly (O'Toole et al. 2000). Current recommendations for baseline investigations and safety monitoring have been produced by ENETS (Oberg et al. 2009), and an up to date review of the role of SSAs has been recently published (Khan \& Caplin 2011).

There are several ongoing trials with pasireotide (SOM230, a novel multitargeted SSA that binds SSTR1-4) for patients with refractory symptoms and palliation for flushing and diarrhoea in patients who are resistant to treatment with octreotide, both as a single agent and in combination with agents such as everolimus (www.clinicaltrials.gov. NCT01364415 Dose escalation study of pasireotide (SOM230) in patients with advanced NETs. (cited 2011), www.clinicaltrials. gov. NCT01263353 Safety and tolerability of pasireotide LAR in combination with everolimus in advanced metastatic NETs (COOPERATE-1). (cited 2011)).

\section{PRRT with radiolabelled SSAs (PRRT)}

PRRT has been used in the treatment of NETs since the early 1990s. The majority of clinical trial data available are from non-randomised retrospective case series; to date, no RCTs have been performed with PRRT. Due to variation in patient selection, dosing, scheduling and total number of treatments, it can be challenging to draw firm conclusions from the literature. There does appear, however, to be a benefit for selected patients with response rates in the range of $40 \%$ (Oberg et al. 2009). Early trials with ${ }^{111}$ In-pentetreotide labelled with somatostatin (the isotope used for Octreoscans) at high cytotoxic doses lead to clinical benefit in only $7 \%$ (Krenning et al. 1993) to 19\% (Buscombe et al. 2003) of patients, this was most likely due to the low tissue penetration of the emitted Auger electrons from the ${ }^{111}$ In isotope (Krenning et al. 1993, Strosberg et al. $2011 a, b)$. Today, the most commonly used isotopes are ${ }^{90}$ yttrium $\left({ }^{90} \mathrm{Y}\right)$ and more recently ${ }^{177}$ lutetium $\left({ }^{177} \mathrm{Lu}\right)$. 
The use of PRRT is recommended for selected metastatic GEP NET patients in specialist centres with expertise and legal permission to manufacture and safely deliver radiolabelled isotopes. In order to be eligible, the patients' tumour should demonstrate at least as high uptake as normal liver on Octreoscan $\left({ }^{111}\right.$ In-pentetreotide). At this time, there are no consistent guidelines regarding optimum dose, cycle interval or safe cumulative dose for these therapies (Kwekkeboom et al. 2009). Treatment schemes and isotopes currently used depend on local expertise, experience and clinical judgement.

\section{${ }^{90}$ Yttrium-labelled PRRT}

${ }^{90}$ Yttrium is a high-energy $\beta$-particle emitter that has a maximum tissue penetration of $12 \mathrm{~mm}$. There are two ${ }^{90}$ yttrium-based isotopes in clinical use $-\left[{ }^{90}\right.$ Y-DOTA$\mathrm{Tyr}^{3}$-octreotide $]\left({ }^{90} \mathrm{Y}\right.$-DOTATOC) and $\left[{ }^{90} \mathrm{Y}\right.$-DOTA $(0)$ D-Phe ${ }^{1}$-Tyr ${ }^{3}$-octreotate] $\left({ }^{90} \mathrm{Y}\right.$-DOTATATE).

The largest study to date using ${ }^{90}$ Y-DOTATOC including 1109 patients found a radiological response (on cross-sectional imaging) in $34.1 \%$ and clinical response in $29.7 \%$. Patients that responded were found to have longer median survival (44.7 vs 18.3 months). The degree of uptake on the pretreatment Octreoscan was found to be predictive of response to treatment and overall survival (Imhof et al. 2011).

${ }^{90}$ Yttrium-labelled lanreotide has also been trialled as it is thought to have higher affinity for $\mathrm{SST}_{3}$ and $\mathrm{SST}_{4}$ than octreotide. However, when used clinically, it was found to have lower affinity for $\mathrm{SST}_{2}$ than ${ }^{90}$ Y-DOTATOC, a response rate of $21 \%$ was observed in a single study of 39 GEP patients (Virgolini et al. 2002). A phase II study of ${ }^{90}$ Y-DOTATATE in 60 GEP NET patients found a PR rate of $23 \%$ with SD observed in the remainder of patients (Cwikla et al. 2010). At 6 months of follow-up, a clinical PR was observed in $72 \%$ of patients. The median overall survival in this patient cohort was 22 months.

Treatment with ${ }^{90} \mathrm{Y}$-DOTATOC and ${ }^{90} \mathrm{Y}$-DOTATATE is generally well tolerated with the most common side effects of nausea and vomiting being caused by the administration of amino acid solutions. Reversible bone marrow suppression is seen in up to $43 \%$ and reversible nephrotoxicity in $10 \%$ of patients (Oberg et al. 2009), rarely myelodysplastic syndrome $(2 \%)$ or acute leukaemia may occur.

\section{${ }^{177}$ Lutetium-labelled PRRT}

${ }^{177}$ Lutetium-octreotate $\left[{ }^{177} \mathrm{Lu}-\mathrm{DOTA}^{0}, \mathrm{Tyr}^{3}\right]$ is a $\beta$ - and $\gamma$-emitting compound that has nine times greater affinity for $\mathrm{SST}_{2}$ than ${ }^{177}$ lutetium-octreotide.
Moreover, tumour uptake is four to five times higher than that seen in normal renal and hepatic tissue. It has lower tissue penetration than ${ }^{90}$ yttrium, making it a desirable isotope for the treatment of smaller tumours/metastases. Response rates of up to $30 \%$ and median time to progression of 40 months have been observed in a study of 310 patients (Kwekkeboom et al. 2008). Again, the degree of uptake in the pretreatment Octreoscan was indicative of response to treatment. ${ }^{177} \mathrm{Lu}$ has the benefit of enabling posttherapy imaging demonstrating localisation of therapy due to its $\gamma$-emissions. For all PRRTs, the longer term toxicity to bone marrow and kidneys needs to be evaluated.

\section{Molecularly targeted therapy}

A number of molecularly targeted agents have been trialled in NETs over the last 10 years, including monoclonal antibodies against EGFR, VEGF, IGF1R and more recently oral tyrosine kinase inhibitors. Initial studies did not routinely stratify patient selection based on the primary site of the tumour and this lead to inconclusive trial outcomes (Faivre et al. 2010). Therefore, patient stratification by primary tumour site and histological grade is key when designing future trials in NETs.

\section{Pancreatic NETs}

\section{VEGF- and mTOR-targeted therapies}

It is well documented that NETs are highly vascularised, and immunohistochemistry studies demonstrate that VEGF and HIF activation markers are over-expressed in pNETs (Zhang et al. 2007, Pape et al. 2011). Secretion of VEGF is inhibited by octreotide and inhibitors of the PI3K/AKT/mTOR pathway (Villaume et al. 2010), suggesting alternative mechanisms of action of these therapies. Initial clinical trials investigating anti-VEGF-related therapy included the use of sorafenib and bevacizumab. More recently, sunitinib has demonstrated improved progression free survival (PFS) in a large phase III RCT when used selectively in pNETs (Raymond et al. 2011a,b).

Sorafenib is a multiple kinase inhibitor affecting VEGFR2, PDGFR (PDGFRB), FGFR1 and FLT3. It was shown to have modest activity in NETs in a phase II study led by Hobday et al. (2007) in which objective response rate (ORR) was $7-11 \%$ in non-selected pancreatic and intestinal NETs. Bevacizumab (an anti-VEGF monoclonal antibody) demonstrated antitumoral activity in mouse models where it inhibited 
tumour angiogenesis and impaired tumour growth (Zhang et al. 2007). However, when trialled clinically alongside SSAs, IFN- $\alpha$ (Yao et al. 2008a,b) and chemotherapy in a phase II trial, improved PFS was observed in the bevacizumab monotherapy arm when compared with IFN $\alpha$ monotherapy. There is now a ongoing phase III trial comparing the PFS of longacting octreotide given concomitantly with either bevacizumab or IFN $\alpha-2 b$ (www.clinicaltrials.gov. NCT00569127 Octreotide and IFN alfa-2b or bevacizumab in treating patients with metastatic or locally advanced, high risk neuroendocrine tumor. (cited 2011)).

In 2011, two pivotal large-scale RCTs were published, which demonstrated an improved progression-free survival in the use of sunitinib (Raymond et al. 2011a,b) and everolimus (Yao et al. 2011) in the treatment of selected patients with low-intermediategrade pNETs. The early phase and phase III trial outcomes are discussed below.

\section{Sunitinib}

Sunitinib is a multiple kinase inhibitor that targets VEGFRs 1-3, platelet-derived growth factor (PDGF) receptor $\alpha$ (PGDFA) and $\beta$ (PGDFA), c-kit, RET and FLT3. It is used in clear cell renal cancers and gastrointestinal stromal tumours as second-line therapy following the failure of imatinib. Preclinical studies on the RIP-Tag2 mouse model of pNETs found that sunitinib decreased tumour mass and inhibited VEGFR-dependent endothelial cell proliferation (Raymond et al. 2009).

The first clinical efficacy of sunitinib in NETs was observed in a phase I study that included three NET patients (Faivre et al. 2007); this was quickly followed by phase II and III trials. Raymond et al. $(2011 a, b)$ have reported early in 2011 on their phase III RCT of $37.5 \mathrm{mg}$ sunitinib given continuously vs best supportive care (BSC) in pNET patients who had metastatic low-intermediate (well-differentiated)-grade tumours that had progressed in the last 12 months. Forty-nine per cent of the patients recruited had functional pNETs. Following positive outcome data for patients on sunitinib therapy at the interim analysis, the trial was terminated early having recruited 171 patients (86 receiving sunitinib and 85 receiving placebo). The primary end point of PFS doubled from 5.5 to 11.4 months in the sunitinib group (HR 0.42; CI 0.26-0.66; $P=0.0001)$. Disease stabilisation was most often observed with an objective response only seen in 9.3\% of cases on sunitinib and $0 \%$ of patients receiving placebo $(P=0.007)$. It was also reported that patient quality of life scores were higher and a delay in the onset of symptoms was observed in the treatment group. Generally, patients receiving sunitinib therapy tolerated the treatment well. The most common toxicities were fatigue, diarrhoea, nausea and vomiting and palmar-plantar erythema. Grade 3-4 toxicities when compared to the placebo group included neutropaenia (12 vs $0 \%$ ), hypertension (10 vs $1 \%$ ) and palmar-plantar erythema (6 vs 0\%). Dose reductions to $25 \mathrm{mg} /$ day were permitted, but mean relative dose intensity was maintained at $91.3 \%$. Following this study, sunitinib is now used in low-intermediate-grade metastatic pNETs that have progressed in the preceding 12 months.

\section{Everolimus and mTOR inhibitors}

Everolimus is an inhibitor of the mTOR, a serine threonine kinase that plays a role in key cellular processes including cell growth, signalling and apoptosis. Activation of mTOR occurs in several cancers. It acts as a signal transductor in the PIK3 pathway and is regulated by the tumour suppressor genes PTEN, NF1 and LKB1 (STK11; Cantley 2002, Shaw \& Cantley 2006). mTOR is also involved in downstream signalling VEGF and IGF1 signalling pathways (Karar \& Maity 2011). Everolimus is approved for use in the treatment of clear cell renal cancer (when sunitinib therapy has failed) and giant cell astrocytoma.

Initial trials of rapamycin and everolimus on neuroendocrine cell lines showed positive results and further preclinical data were obtained using the RIPTag2 pNET mouse model (Grozinsky-Glasberg et al. 2008a,b, Moreno et al. 2008, Chiu et al. 2010). In this study, mice were treated with rapamycin (mTOR inhibitor) alone and in combination with the epidermal growth factor receptor (EGFR) inhibitor erlotinib. Monotherapy with rapamycin led to prolonged PFS, whereas the addition of erlotinib increased overall survival (OS). Phase II and III trials of monotherpay with everolimus were already underway when these data were published. Yao et al. (2011) reported the outcome of the phase III RCT of everolimus in metastatic low-intermediate-grade pNETs in early 2011 (RADIANT 3 Trial). When compared with the phase II sunitinib study, a very similar improved PFS was observed in the everolimus-treated group (11.4 vs 5.4 months; $P<0.0001)$ with no reported improvement of OS to date. Two hundred and seven patients were treated with $10 \mathrm{mg}$ everolimus continuously and 203 received BSC. Patients could crossover to the treatment arm on progression. An objective response 
to everolimus was seen in $4.8 \%$ patients vs $2.0 \%$ in the placebo group - with the majority of patients experiencing disease stabilisation (78\% everolimustreated patients vs $53 \%$ on placebo). A subgroup of patients in this study was treated concomitantly with SSAs, the PFS was not statistically significant between everolimus monotherapy and concomitant therapy with SSAs. It was also noted that improved glycaemic control was observed in patients with functioning insulinoma. Everolimus therapy was well tolerated with the most common side effects being stomatitis, rash, diarrhoea, fatigue and upper respiratory tract infections. Grade 3-4 toxicities when compared with the placebo group were stomatitis (7 vs $0 \%$ ), anaemia (6 vs $0 \%$ ) and hyperglycaemia (5 vs $2 \%$ ).

Grade 3-4 toxicities were similar in both RADIANT 2 and 3 trials of everolimus and include stomatitis (7\%), diarrhoea (3-6\%), fatigue $(2-7 \%)$, infections $(2-5 \%)$ and rash $(1 \%)$. In the event of significant toxicity, dose reduction of everolimus to $5 \mathrm{mg}$ /day, then $5 \mathrm{mg}$ alternate days, was permitted (in RADIANT 3 , dose adjustments were required by $59 \%$ of patients, and in RADIANT 2, drug-related adverse events led to study discontinuation in $19 \%$ of the everolimus group). See Table 2 for an overview of toxicities and clinical monitoring required when treating patients with sunitinib and everolimus.

The UKINETS guidelines for the management of GEP NETs state that sunitinib or everolimus may be used as a line of therapy for patients with advanced (inoperable or metastatic) progressive (radiological evidence of disease progression within 12 months), well-differentiated pNETs (level of evidence 1, grade of recommendation A; Ramage et al. 2012). The more recently published ENETS guidelines recommend that everolimus may be used after failure of chemotherapy in pNET, and in extrapancreatic NET when other treatment options have failed. Sunitinib is also recommended as second- or third-line therapy for pNET but not for extrapancreatic NET due to the lack of any trials supporting efficacy in this setting (Pavel et al. 2011a,b).

\section{Intestinal NETs}

Pavel et al. $(2011 a, b)$ have recently published data from the cohort of patients with intestinal NETs (with carcinoid syndrome) recruited to the RADIANT2 trial of everolimus vs placebo. The primary tumour site in this cohort was predominantly of small intestinal origin (51-53\% of participants). The majority of patients had low-intermediate-grade (well-differentiated) tumours (77-82\%) and 94\% were of PS 0-1. Progression-free survival improved from $11.3 \mathrm{~m}$ with octreotide LAR plus placebo to $16.4 \mathrm{~m}$ with everolimus and octreotide LAR (HR 0.77, 95\% CI 0.59-1.00, $P=0.026$ ). The most common toxicities in the everolimus + octreotide LAR group when compared with the octreotide LAR monotherapy group were stomatitis (62 vs $14 \%$ ), rash (37 vs 12\%), fatigue (31 vs $23 \%$ ) and diarrhoea (27 vs $16 \%)$. Prespecified subgroup analyses showed consistent benefit in differing primary tumour sites, regardless of previous chemotherapy treatment. Biochemical responses including chromogranin $\mathrm{A}(\mathrm{CgA})$ and urinary 5-HIAA were also significant allowing for easily accessible monitoring of response in a clinical setting, toxicity was consistent with previous reports. The trial did not report impact on symptoms or patientreported outcomes, and overall survival will be impacted by the high rate of crossover from the placebo to treatment arm.

Table 2 Summary of clinical safety monitoring and toxicity assessment for the use of molecularly targeted therapies in patients with neuroendocrine tumours

\begin{tabular}{|c|c|c|}
\hline & Sunitinib & Everolimus \\
\hline Pretreatment evaluation & $\begin{array}{l}\text { Adequate bone marrow, renal and liver function } \\
\text { (adequate thyroid function). Blood pressure } \\
\text { within normal limits. LVEF }>50 \% \text {. No ongoing } \\
\text { cardiac arrhythmias, or recent thromboembolic } \\
\text { disease. Performance status } 0-2\end{array}$ & $\begin{array}{l}\text { Adequate bone marrow, renal and liver function. } \\
\text { Adequate lipid concentrations }\end{array}$ \\
\hline $\begin{array}{l}\text { On treatment frequency } \\
\text { of visits }\end{array}$ & Initial 2 week toxicity check, 4 weekly when stable & Initial 2 week toxicity check, 4 weekly when stable \\
\hline Expected toxicities & $\begin{array}{l}\text { Neutropaenia, diarrhoea, asthenia, erythrody- } \\
\text { sesthesia, hypertension, thrombocytopaenia }\end{array}$ & $\begin{array}{l}\text { Stomatitis, rash, fatigue, diarrhoea, hyperglycae- } \\
\text { mia, thrombocytopaenia, injections, pneumoni- } \\
\text { tis, hypercholesterolaemia }\end{array}$ \\
\hline $\begin{array}{l}\text { On treatment safety } \\
\text { monitoring investi- } \\
\text { gations }\end{array}$ & $\begin{array}{l}\text { Clinical examination, vital sign measurement, } \\
\text { haematological and biochemistry assessment }\end{array}$ & $\begin{array}{l}\text { Clinical examination, vital sign measurement, } \\
\text { haematological and biochemistry assessment. } \\
\text { Chest radiograph every } 12 \text { weeks }\end{array}$ \\
\hline
\end{tabular}

LVEF, left ventricular ejection fraction. 


\section{Other pathways that have been targeted in both pancreatic and intestinal NETs Epidermal growth factor receptor}

The EGFR pathway has been previously investigated as a therapeutic target in NETs with limited success. It has been demonstrated that both pulmonary and GEP NETs frequently express EGFR (Shah et al. 2006, Rickman et al. 2009). Following the observation in the preclinical RIP-Tag2 mouse model that the addition of the EGFR inhibitor erlotinib improved overall survival when used concomitantly with mTOR inhibition (Chiu et al. 2010), a phase II clinical trial is currently in progress and due to complete in December 2012 (www.clinicaltrials.gov. NCT0084 3531 RAD001 and erlotinib in patients with NETs. 2012; Available from: http://www.clinicaltrials.gov/ ct2/results?term $=$ NCT00843531).

\section{IGF pathway}

The IGF system is known to be implicated in the development of several solid tumours including colorectal and breast cancer. Activation of the IGF pathway leads to malignant transformation, increased metastatic potential and activation of VEGF through the HIF response mechanism. GEP NETs are known to express IGFs and their receptors (Wulbrand et al. 2000). In vitro studies using the BON1 pancreatic lymph node metastasis cell line found that active IGF1 and IGF1R were expressed and that the addition of IGF1 leads to increased excretion of $\mathrm{CgA}$ by the cell line (von Wichert et al. 2000).

Based on these observations, there are ongoing clinical trials investigating the activity of the IGF1R monoclonal antibody Cetuximab in NETs. See Table 3 for summary.

\section{Novel molecularly targeted therapies under investigation}

There are currently 15 phase II and three phase I trials of molecularly targeted therapy in NETs registered with Clinical Trials.gov recruiting globally (reviewed in Table 3; http://www.clinicaltrials.gov). The following agents are of particular interest.

\section{Pazopanib}

Pazopanib is an orally available angiogenesis inhibitor that targets VEGFR1, -2 and -3 ; PDGFR $\alpha$ and $-\beta$; and $c$-kit. It was approved by FDA for the treatment of renal cell carcinoma in 2009. It has a similar side effect and toxicity profile as sunitinib but is reported to be better tolerated, and it is a desirable novel agent due to its targeting of multiple VEGFRs. Current phase II trials in progress include monotherapy in lowintermediate-grade NETs (www.clinicaltrials.gov. NCT 01099540 Study of pazopanib monotherapy in patients with unresectable, metastatic NET. 2012; Available from: http://www.clinicaltrials.gov/ct2/ results?term $=\mathrm{NCT}+01099540+$. , www.clinicaltrials.gov. NCT 01280201 Pazopanib as single agent in advanced NETs. 2012; Available from: NCT 01280201), both these studies include NETs of pancreatic, intestinal and bronchial origin. Trials of pazopanib in combination with other agents include temozolomide in pNETs (www.clinicaltrials.gov. NCT 01465659 Temozolomide and pazopanib hydrochloride in treating patients with advanced pNETs that cannot be removed by surgery. 2012; Available from: http://www.clinicaltrials.gov/ct2/results?term = $\mathrm{NCT}+01465659)$ and everolimus during embolisation with SIR spheres (www.clinicaltrials.gov. NCT 01469572 Pasireotide, everolimus and selective internal radioembolisation therapy for unresectable hepatic metastases. 2012; Available from: http://www. clinicaltrials.gov/ct2/results?term $=\mathrm{NCT}+01469572$ ).

\section{Brivanib}

Brivanib is a novel agent with dual-inhibitor activity of FGF and VEGF, which shows activity and improves survival in the RIP-Tag2 mouse model of pNETs both first-line and after failure of sorafenib therapy (Allen et al. 2011). This agent is planned for further clinical evaluation in early phase trials.

\section{Cabozantinib}

Cabozantinib is another novel small molecule kinase inhibitor that inhibits MET and VEGFR2 and has been shown to suppress metastasis, angiogenesis and tumour growth in early phase trials (Yakes et al. 2011), an open-label phase II study in advanced pancreatic and GI NETs is due to open shortly (www.clinicaltrials. gov. NCT 01466036 Cabozantinib in advanced pancreatic neuroendocrine and carcinoid tumours. 2012; Available from: http://www.clinicaltrials.gov/ ct2/results?term $=01466036$ ).

\section{Future considerations}

It is now widely accepted that both sunitinib and everolimus can be used in selected metastatic pNET patients of low-intermediate-grade who have progressed in the last 12 months. Recent data from the RADIANT 2 trial also suggest that everolimus 
Table 3 Review of molecularly targeted therapies under investigation in NETs

\begin{tabular}{|c|c|c|c|c|}
\hline Agent & Targets & Phase & Trial details & NCT identifier \\
\hline \multirow[t]{3}{*}{ Pazopanib } & $\begin{array}{l}\text { VEGFR } 1-3, \text { PDGF } \alpha \\
\text { and }-\beta, c-k i t\end{array}$ & II & $\begin{array}{l}\text { Monotherapy in low-intermediate-grade pancreatic, } \\
\text { intestinal and bronchial NETs }\end{array}$ & $\begin{array}{l}\text { NCT } 01099540 \\
\text { NCT } 01280201\end{array}$ \\
\hline & $\begin{array}{l}\text { VEGFR1-3, PDGF } \alpha \\
\text { and }-\beta, \text { c-kit }\end{array}$ & I-II & In combination with temozolomide in pancreatic NETs & NCT 01465659 \\
\hline & $\begin{array}{l}\text { VEGFR } 1-3, \text { PDGF } \alpha \\
\text { and }-\beta, \text { c-kit }\end{array}$ & I-II & $\begin{array}{l}\text { In combination with everolimus in SIR sphere radio- } \\
\text { embolisation }\end{array}$ & NCT 01469572 \\
\hline Axitinib & $\begin{array}{l}\text { VEGFR1-3, PDGF } \beta \text {, } \\
\text { c-kit }\end{array}$ & II & $\begin{array}{l}\text { Monotherapy single-arm study in low-intermediate- } \\
\text { grade NETs of all types }\end{array}$ & NCT 01435122 \\
\hline \multirow[t]{6}{*}{ Everolimus } & mTOR & II & $\begin{array}{l}\text { RAMSETE single-arm trial of everolimus monotherapy } \\
\text { in low-intermediate-grade, metastatic, non- } \\
\text { syndromic NETs }\end{array}$ & NCT 00688623 \\
\hline & mTOR & II & $\begin{array}{l}\text { In combination with carboplatin/paclitaxel in bronchial } \\
\text { NETs/large cell lung cancer }\end{array}$ & NCT 01317615 \\
\hline & mTOR & II & $\begin{array}{l}\text { In combination with erlotinib in low-intermediate- } \\
\text { grade pancreatic NETs or paraganglioma } \\
\text { (carcinoids excluded from April 2011) }\end{array}$ & NCT 00843531 \\
\hline & mTOR & $\mathrm{lb}$ & $\begin{array}{l}\text { Monotherapy in Chinese patients with advanced } \\
\text { pulmonary NET }\end{array}$ & NCT 01324492 \\
\hline & mTOR & II & $\begin{array}{l}\text { Randomised in combination with octreotide }+/- \\
\text { bevacizumab in pancreatic NETs }\end{array}$ & NCT 01229943 \\
\hline & mTOR & I-II & $\begin{array}{l}\text { In combination with pasireotide LAR in low- } \\
\text { intermediate-grade lung or gastroenteropancreatic } \\
\text { metastatic NETs (COOPERATE } 1 \text { and } 2 \text { studies). } \\
\text { Phase II study in pancreatic NETs only }\end{array}$ & $\begin{array}{l}\text { NCT01263353 } \\
\text { NCT } 01374451\end{array}$ \\
\hline Temsirolimus & mTOR & II & $\begin{array}{l}\text { In combination with bevacizumab in low-intermediate- } \\
\text { grade pancreatic and intestinal NETs }\end{array}$ & NCT 01010126 \\
\hline Cixutumumab & $\begin{array}{l}\text { IGF1 receptor mono- } \\
\text { clonal antibody }\end{array}$ & I & $\begin{array}{l}\text { In combination with everolimus and octreotide in low- } \\
\text { intermediate-grade NETs }\end{array}$ & NCT 01204476 \\
\hline Cabozantinib & MET, VEGFR2 & II & $\begin{array}{l}\text { Monotherapy single-arm study in advanced low- } \\
\text { intermediate-grade pancreatic and intestinal NETs }\end{array}$ & $\begin{array}{l}\text { NCT } 01466036 \\
\text { (recruiting from } \\
\text { 2012) }\end{array}$ \\
\hline
\end{tabular}

VEGFR, vascular endothelial growth factor receptor; PDGF, platelet-derived growth factor; c-kit, a receptor tyrosine kinase; SIR, selective internal radiation; mTOR, mammalian target of rapamycin; IGF, insulin like growth factor; MET, a receptor tyrosine kinase.

improves PFS in intestinal NETs; however, this therapy is not approved by FDA at this time. What is unknown is whether these or similar agents are beneficial in other NET histological groups including bronchial NETs and metastatic paraganglioma and whether they would improve clinical outcome in other clinical scenarios such as adjuvant therapy.

\section{Scheduling of molecularly targeted therapy}

One of the major challenges associated with the approval of new cancer therapies is to determine their optimal role alongside existing management protocols. This is particularly challenging in rare tumours such as NETs where there is a lack of largescale RCTs to provide a 'gold standard' to work against. Alongside this, in NETs, there are a number of different systemic therapies available often making optimal scheduling difficult to determine.

To date, sunitinib and everolimus have shown benefit in patients with advanced or metastatic disease with low- and intermediate-grade (well-differentiated) tumours as monotherapy or in combination with SSAs. Historically, streptozocin-based chemotherapy has been beneficial to selected pNET patients with significantly higher RR than those observed with sunitinib and everolimus. It is not known whether treatment with molecularly targeted therapy either before or after chemotherapy improves PFS and quality of life. A European clinical trial is planned to address this question.

It also remains to be determined whether concurrent treatment with targeted therapy and chemotherapy, or of multiple targeted agents, is feasible in terms of toxicity, or warranted in terms of clinical benefit. There is some evidence that combinations of targeted agents lead to unmanageable toxicity, which has in the past led to early termination of trials (Chan et al. 2010) (www.clinicaltrials.gov, NCT00947167 A phase II study of pertuzumab and erlotinib for metastatic or unresectable NETs. 2011). There is a phase I/II study 
currently recruiting to assess the safety and efficacy of the combination of temozolomide with pazopanib in patients with pNET (www.clinicaltrials.gov. NCT 01465659 Temozolomide and pazopanib hydrochloride in treating patients with advanced pNETs that cannot be removed by surgery. 2012; Available from: http://www.clinicaltrials.gov/ct2/results?term = $\mathrm{NCT}+01465659)$.

\section{Adjuvant therapy}

There is currently no standard adjuvant treatment recommended for NETs following curative surgery (with the exception of goblet cell intestinal tumours), the current 5-year overall survival rate after resection of pNETs is 59.3\% (Bilimoria et al. 2008).

The use of molecularly targeted treatments in the adjuvant setting is an interesting concept; however at this time, we lack comprehensive global PFS, OS and outcome data, which is required to plan adequately powered adjuvant therapy clinical trials. The collection of this data is necessary in order to identify those patients at highest risk of recurrence who might benefit from this therapy.

\section{Non-pNETs}

The role of targeted treatments in patients with nonpNETs is evolving. Preclinical models of bronchial carcinoid cells showed inhibition of growth with everolimus treatment (Zatelli et al. 2010). The 44 patients with bronchial NET in the RADIANT 2 trial showed benefit consistent with the general study population: an improvement in PFS from 5.4 to 13.6 months (Pavel et al. 2011a,b). This evidence needs to be further validated in a larger patient cohort in order to confirm the role of everolimus in treatment of bronchial NET, which comprises $\sim 30 \%$ of the total NET patient population.

The RADIANT 2 trial provided stronger evidence for the use of everolimus in gastrointestinal NET as the majority of patients involved in the study had GI NET and had a clinical significant benefit in PFS of 5.1 months. This is a particularly important finding given that GI NETs are less chemosensitive than pNETs. Carcinoid syndrome is present in $<20 \%$ of patients with intestinal NETs (Khan \& Caplin 2011), and the outcome of the RAMSETE trial looking at the impact of everolimus on non-functioning NETs is awaited.

Sunitinib has been used with some clinical effect in metastatic paraganglioma and pheochromocytoma patients following a series of case reports globally. There is increasing preclinical evidence to suggest the use of angiogenic molecularly targeted therapy in this tumour type (Joshua et al. 2009), and there are two ongoing phase II trials globally investigating the use of sunitinib monotherapy (SNIPP Trial (www.clinicaltrials.gov. NCT 00843037 Study of sunitinib in patients with recurrent paraganglioma/phaeochromocytoma. 2012; Available from: http://www.clinicaltrials.gov/ct2/results?term $=$ NCT00843037) and FIRSTMAPP Trial (www.clinicaltrials.gov. NCT 01371201 First international randomized study in malignant progressive phaeochromocytoma and paraganglioma (FIRSTMAPPP). 2012; Available from: http://www.clinicaltrials.gov/ct2/show/NCT013712 01 ?term $=$ sunitinib + paraganglioma\&rank $=2)$ ).

\section{High-grade tumours}

The role of molecularly targeted agents in metastatic poorly differentiated NETs of any origin is unclear. It is usually recommended that these cases are treated with first-line chemotherapy. All the phase III trials to date included well- or moderately differentiated (low- or intermediate-grade) tumours. We know that the underlying genetic and epigenetic changes in these tumours differ depending on grade and this may affect response to targeted treatments. Currently, there is no evidence to support the use of either everolimus or sunitinib in high-grade NETs; however, concomitant therapy with chemotherapy may improve clinical outcome if the combined toxicity is tolerated.

\section{Toxicity management and patient selection}

A further challenge in treating patients undergoing these treatments will be managing toxicity, particularly if patients are to remain on treatment for a number of months. The toxicity profiles of both drugs are well documented in the setting of renal cancer, and the adverse events profile noted during the phase III trials in NETs did not demonstrate any unexpected toxicities. However, it remains to be seen whether hypertension can be used as a surrogate biomarker of response (as it is in renal cell cancer) in NET, and whether management of such toxicities requires specific measures in this patient population.

To date, the majority of patients enroled in the large RCTs have been of good PS (ECOG 0-1). The RADIANT 3 trial included six PS2 patients in each of the treatment and placebo arms (3\% enrolled patients) and the sunitinib trial enrolled one PS2 patient in total. Whilst some patients experience severe fatigue on these therapies, others can tolerate treatment with minimal toxicity; therefore in selected PS2 patients, an improvement in PFS and symptomatic control might be achievable with these treatments. 


\section{Molecular markers for response to treatment}

It is recommended that 'conventional' biomarkers such as chromogranin-A, urinary 5-HIAA and gut hormones where appropriate are used to monitor response to therapy. However, there is a real need to identify and introduce novel biomarkers to aid diagnosis, treatment stratification and predict response to systemic therapy.

Reduced levels of O(6)-methylguanine DNA methyltransferase (MGMT) expression has been associated with response to temozolomide in other solid tumours such as glioma. A study by Kulke et al. (2009) examined MGMT expression in PNETs undergoing treatment with temozolomide. This found reduced expression of MGMT in 51\% of PNETs (this was not correlated with grade of tumour). When compared with those tumours expressing MGMT, the MGMT-deficient tumours had a significantly higher response rate to temozolomide-based chemotherapy. This immunohistochemistry-based marker shows promise, but at this time requires further validation in larger cohorts.

Circulating tumour cells (CTCs) are emerging as a novel biomarker in NETs, their presence is associated with poorer overall survival and they may have a role in determining response to systemic therapies including chemotherapy, PRRT and molecularly targeted therapy (Khan et al. 2011). In prostate cancer, the number of CTCs in patients responding to systemic therapy falls sharply and quickly after commencing therapy; therefore, if the same were to happen in NETs, potentially toxic therapies could be stopped earlier, rather than waiting for 3 monthly interval scanning.

\section{Novel agents}

Novel agents targeting the PI3K/AKT/mTOR pathway are in development, and early trials including PI3K inhibitors (Zitzmann et al. 2010), IGF1R monoclonal antibodies (Mendivil et al. 2011) and secondgeneration mTORC1/mTORC2 inhibitors are in progress (Jessen et al. 2009). These agents show promise but require further validation in the context of large randomised phase III trials. Following a meeting of the NET Task force NCI GI steering committee in 2011, it has been recommended that PFS can be used as a relevant primary endpoint in phase II and III trials as NETs (particularly of low and intermediate grade) often have a long OS and PFS, particularly as the observed radiological RR is low with molecularly targeted therapies (Kulke et al. 2011).

\section{Conclusions}

The molecularly targeted therapies everolimus and sunitinib have been rationally and successfully applied to the treatment of low-intermediate-grade pNETs. Everolimus was shown to improve progression-free survival by 6.4 months in pNET and 5.1 months in patients with carcinoid syndrome (including gastrointestinal and bronchial NETs). Recently, everolimus has also shown to improve PFS in small intestinal NETs. Sunitinib has demonstrated a similar improvement in PFS of 5.9 months in pNET, novel agents targeted to VEGF as well as mTOR/PI3k/AKT pathway are in development.

With the current evidence available, we propose that sunitinib and everolimus (with SSAs in symptomatic patients) can be used in metastatic low-intermediategrade pNETs that have progressed in the previous 12 months. It is reasonable to consider changing therapy from sunitinib to everolimus (and vice versa) at progression, although currently there is no clinical trial data to support this. There is increasing evidence supporting the activity of everolimus in intestinal and bronchial NETs; however, there is no FDA approval for the use of everolimus for those patient groups.

What remains to be determined is the exact scheduling of molecularly targeted therapy around other systemic therapies, particularly chemotherapy, clinical trials are planned to address this. Currently, there is no evidence to support the use of adjuvant therapy, and trial outcome data are awaited for the combined use of temozolomide and pazopanib.

In order to optimise patient selection and clinical outcome, identification of predictive and prognostic biomarkers of response for these agents is required. The costs of the systemic therapies discussed in this review vary greatly with PRRT costing up to $£ 25000$ (\$40 000) for a full course of treatment, sunitinib/everolimus costing $£ 2500$ (\$4000) per month and chemotherapy costing $\sim £ 800$ (\$1280) per course. Although the cost of therapy should not determine the choice of treatment, it has implications in countries with public-funded health care systems where restrictions exist in funding certain cancer therapies.

Historically, NET clinical trials did not always distinguish between intestinal NETs from pNETs, as it has only more recently been determined that the biology underlying these two tumour groups is markedly different. This led to inconclusive outcome data from earlier trials. It is now recommended that gastrointestinal, pancreatic and other NETs are treated as separate entities in future clinical trials. Moreover, it has been clearly demonstrated that large-scale phase III 
trials are feasible through international collaboration in this rare tumour type and should be continued.

Whilst we are beginning to determine the genetics and pathogenesis of pNETs and utilise molecularly targeted treatment in this disease outside of the research setting, our understanding of gastrointestinal and bronchial NETs requires further development. We await results from large-scale integrated genomic analyses of NET subgroups that will guide the identification of novel clinical biomarkers, relevant signalling pathways and therapeutic targets. With the introduction of the first oral molecularly targeted therapies in pNETs, personalised NET treatment is becoming a reality. Integrated biomarker studies should be incorporated in to clinical trials in order to identify the best biomarkers in response to treatment and overall prognosis. This will prevent our patients receiving therapies that have significant toxicities unnecessarily and guide them towards truly personalised cancer treatment.

\section{Declaration of interest}

The authors declare that there is no conflict of interest that could be perceived as prejudicing the impartiality of the research reported.

\section{Funding}

This research did not receive any specific grant from any funding agency in the public, commercial or not-for-profit sector. Two of the authors are funded by Cancer Research UK and The Raymond and Beverly Sackler Foundation.

\section{References}

Akerstrom G, Hessman O, Hellman P \& Skogseid B 2005 Pancreatic tumours as part of the MEN-1 syndrome. Best Practice \& Research. Clinical Gastroenterology 19 819-830. (doi:10.1016/j.bpg.2005.05.006)

Allen E, Walters IB \& Hanahan D 2011 Brivanib, a dual FGF/VEGF inhibitor, is active both first and second line against mouse pancreatic neuroendocrine tumors developing adaptive/evasive resistance to VEGF inhibition. Clinical Cancer Research 17 5299-5310. (doi:10.1158/1078-0432.CCR-10-2847)

Anderson T, Schein PS, McMenamin MG \& Cooney DA 1974 Streptozotocin diabetes. Correlation with extent of depression of pancreatic islet nicotinamide adenine dinucleotide. Journal of Clinical Investigation 54 672-677. (doi:10.1172/JCI107805)

Arnold R, Rinke A, Klose KJ, Müller HH, Wied M, Zamzow K, Schmidt C, Schade-Brittinger C, Barth P, Moll R et al. 2005 Octreotide versus octreotide plus interferon- $\alpha$ in endocrine gastroenteropancreatic tumors: a randomized trial. Clinical Gastroenterology and Hepatology 3 761-771. (doi:10.1016/S1542-3565(05)00481-7)

di Bartolomeo M, Bajetta E, Buzzoni R, Mariani L, Carnaghi C, Somma L, Zilembo N \& di Leo A 1996 Clinical efficacy of octreotide in the treatment of metastatic neuroendocrine tumors. A study by the Italian Trials in Medical Oncology Group. Cancer 77 402-408. (doi:10.1002/(SICI)10970142(19960115)77:2<402::AID-CNCR25>3.0.CO;2-4)

Bilimoria KY, Talamonti MS, Tomlinson JS, Stewart AK, Winchester DP, Ko CY \& Bentrem DJ 2008 Prognostic score predicting survival after resection of pancreatic neuroendocrine tumors: analysis of 3851 patients. Annals of Surgery 247 490-500. (doi:10.1097/SLA. 0b013e31815b9cae)

Blansfield JA, Choyke L, Morita SY, Choyke PL, Pingpank JF, Alexander HR, Seidel G, Shutack Y, Yuldasheva N, Eugeni M et al. 2007 Clinical, genetic and radiographic analysis of 108 patients with von Hippel-Lindau disease (VHL) manifested by pancreatic neuroendocrine neoplasms (PNETs). Surgery 142 814-818 (discussion 818.e1-2). (doi:10.1016/j.surg.2007.09.012)

Brandi ML, Gagel RF, Angeli A, Bilezikian JP, Beck-Peccoz P, Bordi C, Conte-Devolx B, Falchetti A, Gheri RG, Libroia A et al. 2001 Guidelines for diagnosis and therapy of MEN type 1 and type 2. Journal of Clinical Endocrinology and Metabolism 86 5658-5671. (doi:10.1210/jc.86.12.5658)

Buscombe JR, Caplin ME \& Hilson AJ 2003 Long-term efficacy of high-activity ${ }^{111}$ In-pentetreotide therapy in patients with disseminated neuroendocrine tumors. Journal of Nuclear Medicine 44 1-6.

Calender A 2006 Genetics of neuroendocrine tumours. In Handbook of Neuroendocrine Tumours, pp 53-81. Eds, M Caplin \& L Kvols. BioScientifica Ltd: Bristol, UK.

Cantley LC 2002 The phosphoinositide 3-kinase pathway. Science 296 1655-1657. (doi:10.1126/science.296.5573. 1655)

Chan JA, Mayer RJ, Jackson N, Malinowski P, Regan E \& Kulke M 2010 Phase I study of sorafenib in combination with everolimus (RAD001) in patients with advanced neuroendocrine tumors (NET). ASCO Meeting Abstracts. Journal of Clinical Oncology 28 (15_suppl) e14597.

Chiu CW, Nozawa H \& Hanahan D 2010 Survival benefit with proapoptotic molecular and pathologic responses from dual targeting of mammalian target of rapamycin and epidermal growth factor receptor in a preclinical model of pancreatic neuroendocrine carcinogenesis. Journal of Clinical Oncology 28 4425-4433. (doi:10.1200/JCO.2010.28.0198)

Couvelard A, O'Toole D, Turley H, Leek R, Sauvanet A, Degott C, Ruszniewski P, Belghiti J, Harris AL, Gatter K et al. 2005 Microvascular density and hypoxia-inducible factor pathway in pancreatic endocrine tumours: negative correlation of microvascular density and VEGF expression with tumour progression. British Journal of Cancer 92 94-101. (doi:10.1038/sj.bjc.6602245) 
Couvelard A, Deschamps L, Rebours V, Sauvanet A, Gatter K, Pezzella F, Ruszniewski P \& Bedossa P 2008 Overexpression of the oxygen sensors PHD-1, PHD-2, PHD-3, and FIH is associated with tumor aggressiveness in pancreatic endocrine tumors. Clinical Cancer Research 14 6634-6639. (doi:10.1158/1078-0432.CCR-07-5258)

Cwikla JB, Sankowski A, Seklecka N, Buscombe JR, Nasierowska-Guttmejer A, Jeziorski KG, Mikolajczak R, Pawlak D, Stepien K, Walecki J et al. 2010 Efficacy of radionuclide treatment DOTATATE Y-90 in patients with progressive metastatic gastroenteropancreatic neuroendocrine carcinomas (GEP-NETs): a phase II study. Annals of Oncology 21 787-794. (doi:10.1093/annonc/ mdp372)

Delaunoit T, Ducreux M, Boige V, Dromain C, Sabourin JC, Duvillard P, Schlumberger M, de Baere T, Rougier P, Ruffie P et al. 2004 The doxorubicin-streptozotocin combination for the treatment of advanced welldifferentiated pancreatic endocrine carcinoma; a judicious option? European Journal of Cancer 40 515-520. (doi:10.1016/j.ejca.2003.09.035)

Ekeblad S, Sundin A, Janson ET, Welin S, Granberg D, Kindmark H, Dunder K, Kozlovacki G, Orlefors H, Sigurd M et al. 2007 Temozolomide as monotherapy is effective in treatment of advanced malignant neuroendocrine tumors. Clinical Cancer Research 13 2986-2991. (doi:10.1158/1078-0432.CCR-06-2053)

Engstrom PF, Lavin PT, Moertel CG, Folsch E \& Douglass HO Jr 1984 Streptozocin plus fluorouracil versus doxorubicin therapy for metastatic carcinoid tumor. Journal of Clinical Oncology 2 1255-1259.

Eriksson B, Annibale B, Bajetta E, Mitry E, Pavel M, Platania M, Salazar R, Plöckinger U \& Mallorca Consensus Conference participants; European Neuroendocrine Tumor Society 2009 ENETS Consensus Guidelines for the Standards of Care in Neuroendocrine Tumors: chemotherapy in patients with neuroendocrine tumors. Neuroendocrinology 90 214-219. (doi:10.1159/000225950)

Faiss S, Scherübl H, Riecken EO \& Wiedenmann B 1996 Interferon- $\alpha$ versus somatostatin or the combination of both in metastatic neuroendocrine gut and pancreatic tumours. Digestion 57 (Suppl 1) 84-85. (doi:10.1159/000201404)

Faiss S, Pape UF, Böhmig M, Dörffel Y, Mansmann U, Golder W, Riecken EO, Wiedenmann B \& International Lanreotide and Interferon Alfa Study Group 2003 Prospective, randomized, multicenter trial on the antiproliferative effect of lanreotide, interferon alfa, and their combination for therapy of metastatic neuroendocrine gastroenteropancreatic tumors - the International Lanreotide and Interferon Alfa Study Group. Journal of Clinical Oncology 21 2689-2696. (doi:10.1200/JCO.2003.12.142)

Faivre S, Demetri G, Sargent W \& Raymond E 2007 Molecular basis for sunitinib efficacy and future clinical development. Nature Reviews. Drug Discovery 6 734-745. (doi:10.1038/nrd2380)
Faivre S, Sablin MP, Dreyer C \& Raymond E 2010 Novel anticancer agents in clinical trials for well-differentiated neuroendocrine tumors. Endocrinology and Metabolism Clinics of North America 39 811-826. (doi:10.1016/j.ecl. 2010.09.006)

Falconi M, Bartsch DK, Eriksson B, Klöppel G, Lopes JM, O'Connor JM, Salazar R, Taal BG, Vullierme MP, O'Toole D et al. 2011 ENETS Consensus Guidelines for the management of patients with digestive neuroendocrine neoplasms of the digestive system. Well-differentiated pancreatic non-functioning tumors. Neuroendocrinology 95 120-134. (doi:10.1159/000335587)

Goldstein R \& Meyer T 2011 Role of everolimus in pancreatic neuroendocrine tumors. Expert Review of Anticancer Therapy 11 1653-1665. (doi:10.1586/era.11.145)

Granberg D, Eriksson B, Wilander E, Grimfjärd P, Fjällskog M-L, Öberg K \& Skogseid B 2001 Experience in treatment of metastatic pulmonary carcinoid tumors. Annals of Oncology 12 1383-1391. (doi:10.1023/ A:1012569909313)

Grozinsky-Glasberg S, Kaltsas G, Gur C, Gal E, Thomas D, Fichman S, Alexandraki K, Barak D, Glaser B, Shimon I et al. 2008 a Long-acting somatostatin analogues are an effective treatment for type 1 gastric carcinoid tumours. European Journal of Endocrinology 159 475-482. (doi:10.1530/EJE-08-0420)

Grozinsky-Glasberg S, Franchi G, Teng M, Leontiou CA, Ribeiro de Oliveira A Jr, Dalino P, Salahuddin N, Korbonits M \& Grossman AB 2008b Octreotide and the mTOR inhibitor RAD001 (everolimus) block proliferation and interact with the Akt-mTOR-p70S6K pathway in a neuro-endocrine tumour cell line. Neuroendocrinology 87 168-181. (doi:10.1159/000111501)

Hammel PR, Vilgrain V, Terris B, Penfornis A, Sauvanet A, Correas JM, Chauveau D, Balian A, Beigelman C, O'Toole D et al. 2000 Pancreatic involvement in von Hippel-Lindau disease. The Groupe Francophone d'Etude de la Maladie de von Hippel-Lindau. Gastroenterology 119 1087-1095. (doi:10.1053/gast.2000.18143)

Hicklin DJ \& Ellis LM 2005 Role of the vascular endothelial growth factor pathway in tumor growth and angiogenesis. Journal of Clinical Oncology 23 1011-1027. (doi:10.1200/JCO.2005.06.081)

Hobday TJ, Rubin J, Holen K, Picus J, Donehower R, Marschke R, Maples W, Lloyd R, Mahoney M \& Erlichman C 2007 MC044h, a phase II trial of sorafenib in patients (pts) with metastatic neuroendocrine tumors (NET): a Phase II Consortium (P2C) study. ASCO Meeting Abstracts. Journal of Clinical Oncology 25 (18_suppl) 4504.

Hofland LJ, de Herder WW, Waaijers M, Zuijderwijk J, Uitterlinden P, van Koetsveld PM \& Lamberts SW 1999 Interferon- $\alpha-2 \mathrm{a}$ is a potent inhibitor of hormone secretion by cultured human pituitary adenomas. Journal of Clinical Endocrinology and Metabolism 84 3336-3343. (doi:10.1210/jc.84.9.3336) 
Huang J \& Manning BD 2008 The TSC1-TSC2 complex: a molecular switchboard controlling cell growth. Biochemical Journal 412 179-190. (doi:10.1042/ BJ20080281)

Imhof A, Brunner P, Marincek N, Briel M, Schindler C, Rasch H, Mäcke HR, Rochlitz C, Müller-Brand J \& Walter MA 2011 Response, survival, and long-term toxicity after therapy with the radiolabeled somatostatin analogue [ ${ }^{90}$ Y-DOTA]-TOC in metastasized neuroendocrine cancers. Journal of Clinical Oncology 29 2416-2423. (doi:10.1200/JCO.2010.33.7873)

Isacoff WH, Moss RA, Pecora AL \& Fine RL 2006 Temozolomide/capecitabine therapy for metastatic neuroendocrine tumors of the pancreas. A retrospective review. ASCO Meeting Abstracts. Journal of Clinical Oncology 24 (18_suppl) 14023.

Jessen K, Wang S, Kessler L, Guo X, Kucharski J, Staunton J, Lan L, Elia M, Stewart J, Brown J et al. 2009 Abstract B148: INK128 is a potent and selective TORC1/2 inhibitor with broad oral antitumor activity. Molecular Cancer Therapeutics 8 (Suppl 1) B148.

Jiao Y, Shi C, Edil BH, de Wilde RF, Klimstra DS, Maitra A, Schulick RD, Tang LH, Wolfgang CL, Choti MA et al. 2011 DAXX/ATRX, MEN1, and mTOR pathway genes are frequently altered in pancreatic neuroendocrine tumors. Science 331 1199-1203. (doi:10.1126/science. 1200609)

Johannessen CM, Reczek EE, James MF, Brems H, Legius E \& Cichowski K 2005 The NF1 tumor suppressor critically regulates TSC2 and mTOR. PNAS 102 8573-8578. (doi:10.1073/pnas.0503224102)

Joshua AM, Ezzat S, Asa SL, Evans A, Broom R, Freeman M \& Knox JJ 2009 Rationale and evidence for sunitinib in the treatment of malignant paraganglioma/pheochromocytoma. Journal of Clinical Endocrinology and Metabolism 94 5-9. (doi:10.1210/jc.2008-1836)

Karar J \& Maity A $2011 \mathrm{PI} 3 \mathrm{~K} / \mathrm{AKT} / \mathrm{mTOR}$ pathway in angiogenesis. Frontiers in Molecular Neuroscience 451. (doi:10.3389/fnmol.2011.00051)

Khan MS \& Caplin ME 2011 Therapeutic management of patients with gastroenteropancreatic neuroendocrine tumours. Endocrine-Related Cancer 18 (Suppl 1) S53-S74. (doi:10.1530/ERC-10-0271)

Khan MS, Tsigani T, Rashid M, Rabouhans JS, Yu D, Luong TV, Caplin M \& Meyer T 2011 Circulating tumor cells and EpCAM expression in neuroendocrine tumors. Clinical Cancer Research 17 337-345. (doi:10.1158/ 1078-0432.CCR-10-1776)

Kolby L, Persson G, Franzén S \& Ahrén B 2003 Randomized clinical trial of the effect of interferon $\alpha$ on survival in patients with disseminated midgut carcinoid tumours. British Journal of Surgery 90 687-693. (doi:10.1002/bjs. 4149)

Kouvaraki MA, Ajani JA, Hoff P, Wolff R, Evans DB, Lozano R \& Yao JC 2004 Fluorouracil, doxorubicin, and streptozocin in the treatment of patients with locally advanced and metastatic pancreatic endocrine carcinomas. Journal of Clinical Oncology 22 4762-4771. (doi:10.1200/JCO.2004.04.024)

Krenning EP, Kwekkeboom DJ, Bakker WH, Breeman WA, Kooij PP, Oei HY, van Hagen M, Postema PT, de Jong M, Reubi JC et al. 1993 Somatostatin receptor scintigraphy with [ ${ }^{111}$ In-DTPA-D-Phe1]- and [ ${ }^{123}$ I-Tyr3]-octreotide: the Rotterdam experience with more than 1000 patients. European Journal of Nuclear Medicine 20 716-731. (doi:10.1007/BF00181765)

Kulke MH, Stuart K, Enzinger PC, Ryan DP, Clark JW, Muzikansky A, Vincitore M, Michelini A \& Fuchs CS 2006 Phase II study of temozolomide and thalidomide in patients with metastatic neuroendocrine tumors.

Journal of Clinical Oncology 24 401-406. (doi:10.1200/ JCO.2005.03.6046)

Kulke MH, Hornick JL, Frauenhoffer C, Hooshmand S, Ryan DP, Enzinger PC, Meyerhardt JA, Clark JW, Stuart K, Fuchs CS et al. 2009 O6-methylguanine DNA methyltransferase deficiency and response to temozolomide-based therapy in patients with neuroendocrine tumors. Clinical Cancer Research 15 338-345. (doi:10.1158/1078-0432.CCR-08-1476)

Kulke MH, Anthony LB, Bushnell DL, de Herder WW, Goldsmith SJ, Klimstra DS, Marx SJ, Pasieka JL, Pommier RF, Yao JC et al. 2010 NANETS treatment guidelines: well-differentiated neuroendocrine tumors of the stomach and pancreas. Pancreas 39 735-752. (doi:10.1097/MPA.0b013e3181ebb168)

Kulke MH, Siu LL, Tepper JE, Fisher G, Jaffe D, Haller DG, Ellis LM, Benedetti JK, Bergsland EK, Hobday TJ et al. 2011 Future directions in the treatment of neuroendocrine tumors: consensus report of the National Cancer Institute Neuroendocrine Tumor clinical trials planning meeting. Journal of Clinical Oncology 29 934-943. (doi:10.1200/ JCO.2010.33.2056)

Kvols LK, Moertel CG, O’Connell MJ, Schutt AJ, Rubin J \& Hahn RG 1986 Treatment of the malignant carcinoid syndrome. Evaluation of a long-acting somatostatin analogue. New England Journal of Medicine $\mathbf{3 1 5}$ 663-666. (doi:10.1056/NEJM198609113151102)

Kwekkeboom DJ, de Herder WW, Kam BL, van Eijck CH, van Essen M, Kooij PP, Feelders RA, van Aken MO \& Krenning EP 2008 Treatment with the radiolabeled somatostatin analog $\left[{ }^{177} \mathrm{Lu}\right.$-DOTA 0,Tyr3]octreotate: toxicity, efficacy, and survival. Journal of Clinical Oncology 26 2124-2130. (doi:10.1200/JCO.2007.15. 2553)

Kwekkeboom DJ, Krenning EP, Lebtahi R, Komminoth P, Kos-Kudła B, de Herder WW, Plöckinger U \& Mallorca Consensus Conference participants; European Neuroendocrine Tumor Society 2009 ENETS Consensus Guidelines for the Standards of Care in Neuroendocrine Tumors: peptide receptor radionuclide therapy with radiolabeled somatostatin analogs. Neuroendocrinology 90 220-226. (doi:10.1159/000225951) 
Lott ST, Chandler DS, Curley SA, Foster CJ, El-Naggar A, Frazier M, Strong LC, Lovell M \& Killary AM 2002 High frequency loss of heterozygosity in von Hippel-Lindau (VHL)-associated and sporadic pancreatic islet cell tumors: evidence for a stepwise mechanism for malignant conversion in VHL tumorigenesis. Cancer Research 62 1952-1955.

Marx SJ 2005 Molecular genetics of multiple endocrine neoplasia types 1 and 2. Nature Reviews. Cancer 5 367-375. (doi:10.1038/nrc1610)

Maton PN, Gardner JD \& Jensen RT 1989 Use of long-acting somatostatin analog SMS 201-995 in patients with pancreatic islet cell tumors. Digestive Diseases and Sciences 34 (3 suppl) 28S-39S. (doi:10.1007/ BF01536043)

Mendivil A, Zhou C, Cantrell LA, Gehrig PA, Malloy KM, Blok LJ, Burger CW \& Bae-Jump VL 2011 AMG 479, a novel IGF-1-R antibody, inhibits endometrial cancer cell proliferation through disruption of the PI3K/Akt and MAPK pathways. Reproductive Sciences 18 832-841. (doi:10.1177/1933719111398501)

Missiaglia E, Dalai I, Barbi S, Beghelli S, Falconi M, della Peruta M, Piemonti L, Capurso G, Di Florio A, delle Fave G et al. 2010 Pancreatic endocrine tumors: expression profiling evidences a role for AKT-mTOR pathway. Journal of Clinical Oncology 28 245-255. (doi:10.1200/JCO.2008.21.5988)

Moertel CG, Hanley JA \& Johnson LA 1980 Streptozocin alone compared with streptozocin plus fluorouracil in the treatment of advanced islet-cell carcinoma. New England Journal of Medicine 303 1189-1194. (doi:10.1056/ NEJM198011203032101)

Moertel CG, Lefkopoulo M, Lipsitz S, Hahn RG \& Klaassen D 1992 Streptozocin-doxorubicin, streptozocinfluorouracil or chlorozotocin in the treatment of advanced islet-cell carcinoma. New England Journal of Medicine 326 519-523. (doi:10.1056/NEJM199202203260804)

Moreno A, Akcakanat A, Munsell MF, Soni A, Yao JC \& Meric-Bernstam F 2008 Antitumor activity of rapamycin and octreotide as single agents or in combination in neuroendocrine tumors. Endocrine-Related Cancer 15 257-266. (doi:10.1677/ERC-07-0202)

Oberg K, Funa K \& Alm G 1983 Effects of leukocyte interferon on clinical symptoms and hormone levels in patients with mid-gut carcinoid tumors and carcinoid syndrome. New England Journal of Medicine 309 129-133. (doi:10.1056/NEJM198307213090301)

Oberg K, Ferone D, Kaltsas G, Knigge UP, Taal B, Plöckinger U \& Mallorca Consensus Conference participants; European Neuroendocrine Tumor Society 2009 ENETS Consensus Guidelines for the Standards of Care in Neuroendocrine Tumors: biotherapy. Neuroendocrinology 90 209-213. (doi:10.1159/000183751)

Oberg K, Hellman P, Kwekkeboom D, Jelic S \& ESMO Guidelines Working Group 2010a Neuroendocrine bronchial and thymic tumours: ESMO Clinical Practice
Guidelines for diagnosis, treatment and follow-up. Annals of Oncology 21 (Suppl 5) v220-v222.

(doi:10.1093/annonc/mdq191)

Oberg K, Akerström G, Rindi G, Jelic S \& ESMO Guidelines Working Group $2010 b$ Neuroendocrine gastroenteropancreatic tumours: ESMO Clinical Practice Guidelines for diagnosis, treatment and follow-up. Annals of Oncology 21 (Suppl 5) v223-v227. (doi:10.1093/annonc/mdq192)

O'Toole D, Ducreux M, Bommelaer G, Wemeau JL, Bouché O, Catus F, Blumberg J \& Ruszniewski P 2000 Treatment of carcinoid syndrome: a prospective crossover evaluation of lanreotide versus octreotide in terms of efficacy, patient acceptability, and tolerance. Cancer 88 770-776. (doi:10.1002/(SICI)1097-0142(20000215)88:4<770:: AID-CNCR6 > 3.0.CO;2-0)

Pape UF, Perren A, Niederle B, Gross D, Gress T, Costa F, Arnold R, Denecke T, Plöckinger U, Salazar R et al. 2011 ENETS Consensus Guidelines for the management of patients with neuroendocrine neoplasms from the jejuno-ileum and the appendix including goblet cell carcinomas. Neuroendocrinology 95 135-156. (doi:10.1159/000335629)

Parmar S \& Platanias LC 2005 Interferons. Cancer Treatment and Research 126 45-68.

Pavel M, Baudin E, Couvelard A, Krenning E, Öberg K, Steinmüller T, Anlauf M, Wiedenmann B, Salazar R \& Barcelona Consensus Conference participants 2011a ENETS Consensus Guidelines for the management of patients with liver and other distant metastases from neuroendocrine neoplasms of foregut, midgut, hindgut, and unknown primary. Neuroendocrinology 95 157-176. (doi:10.1159/000335597)

Pavel ME, Hainsworth JD, Baudin E, Peeters M, Hörsch D, Winkler RE, Klimovsky J, Lebwohl D, Jehl V, Wolin EM et al. $2011 b$ Everolimus plus octreotide long-acting repeatable for the treatment of advanced neuroendocrine tumours associated with carcinoid syndrome (RADIANT-2): a randomised, placebo-controlled, phase 3 study. Lancet 378 2005-2012. (doi:10.1016/S0140-6736(11)61742-X)

Ramage JK, Ahmed A, Ardill J, Bax N, Breen DJ, Caplin ME, Corrie P, Davar J, Davies AH, Lewington V et al. 2012 Guidelines for the management of gastroenteropancreatic neuroendocrine (including carcinoid) tumours (NETs). Gut 61 6-32. (doi:10.1136/gutjnl-2011-300831)

Raymond E, Faivre S, Hammel P \& Ruszniewski P 2009 Sunitinib paves the way for targeted therapies in neuroendocrine tumors. Targeted Oncology 4 253-254. (doi:10.1007/s11523-009-0130-0)

Raymond E, Dahan L, Raoul J-L, Bang Y-J, Borbath I, Lombard-Bohas C, Valle J, Metrakos P, Smith D, Vinik A et al. 2011a Sunitinib malate for the treatment of pancreatic neuroendocrine tumors. New England Journal of Medicine 364 501-513. (doi:10.1056/ NEJMoa1003825)

Raymond E, Hobday T, Castellano D, Reidy-Lagunes D, García-Carbonero R \& Carrato A $2011 b$ Therapy 
innovations: tyrosine kinase inhibitors for the treatment of pancreatic neuroendocrine tumors. Cancer Metastasis Reviews 30 (Suppl 1) 19-26.

Rickman OB, Vohra PK, Sanyal B, Vrana JA, Aubry MC, Wigle DA \& Thomas CF Jr 2009 Analysis of ErbB receptors in pulmonary carcinoid tumors. Clinical Cancer Research 15 3315-3324. (doi:10.1158/1078-0432.CCR-08-2549)

Rinke A, Müller H-H, Schade-Brittinger C, Klose K-J, Barth P, Wied M, Mayer C, Aminossadati B, Pape U-F, Bläker M et al. 2009 Placebo-controlled, double-blind, prospective, randomized study on the effect of octreotide LAR in the control of tumor growth in patients with metastatic neuroendocrine midgut tumors: a report from the PROMID Study Group. Journal of Clinical Oncology 27 4656-4663. (doi:10.1200/JCO.2009.22.8510)

Rubin J, Ajani J, Schirmer W, Venook AP, Bukowski R, Pommier R, Saltz L, Dandona P \& Anthony L 1999 Octreotide acetate long-acting formulation versus openlabel subcutaneous octreotide acetate in malignant carcinoid syndrome. Journal of Clinical Oncology 17 600-606.

Ruszniewski P, Ducreux M, Chayvialle JA, Blumberg J, Cloarec D, Michel H, Raymond JM, Dupas JL, Gouerou H, Jian R et al. 1996 Treatment of the carcinoid syndrome with the longacting somatostatin analogue lanreotide: a prospective study in 39 patients. Gut 39 279-283. (doi:10.1136/gut.39.2.279)

Schmitt AM, Schmid S, Rudolph T, Anlauf M, Prinz C, Klöppel G, Moch H, Heitz PU, Komminoth P \& Perren A 2009 VHL inactivation is an important pathway for the development of malignant sporadic pancreatic endocrine tumors. Endocrine-Related Cancer 16 1219-1227. (doi:10.1677/ERC-08-0297)

Semenza GL 2003 Targeting HIF-1 for cancer therapy. Nature Reviews. Cancer 3 721-732. (doi:10.1038/nrc1187)

Shah T, Hochhauser D, Frow R, Quaglia A, Dhillon AP \& Caplin ME 2006 Epidermal growth factor receptor expression and activation in neuroendocrine tumours. Journal of Neuroendocrinology 18 355-360. (doi:10.1111/j.1365-2826.2006.01425.x)

Shaw RJ \& Cantley LC 2006 Ras, PI(3)K and mTOR signalling controls tumour cell growth. Nature 441 424-430. (doi:10.1038/nature04869)

Srirajaskanthan R, Toumpanakis C, Karpathakis A, Marelli L, Quigley AM, Dusmet M, Meyer T \& Caplin ME 2009 Surgical management and palliative treatment in bronchial neuroendocrine tumours: a clinical study of 45 patients. Lung Cancer 65 68-73. (doi:10.1016/j.lungcan.2008.10.025)

Strosberg JR, Fine RL, Choi J, Nasir A, Coppola D, Chen DT, Helm J \& Kvols L 2011 $a$ First-line chemotherapy with capecitabine and temozolomide in patients with metastatic pancreatic endocrine carcinomas. Cancer 117 268-275. (doi:10.1002/cncr.25425)

Strosberg JR, Cheema A \& Kvols LK $2011 b$ A review of systemic and liver-directed therapies for metastatic neuroendocrine tumors of the gastroenteropancreatic tract. Cancer Control 18 127-137.
Sun W, Lipsitz S, Catalano P, Mailliard JA, Haller DG \& Eastern Cooperative Oncology Group 2005 Phase II/III study of doxorubicin with fluorouracil compared with streptozocin with fluorouracil or dacarbazine in the treatment of advanced carcinoid tumors: Eastern Cooperative Oncology Group Study E1281. Journal of Clinical Oncology 23 4897-4904. (doi:10.1200/JCO.2005.03.616)

Tomassetti P, Migliori M, Caletti GC, Fusaroli P, Corinaldesi R \& Gullo L 2000 Treatment of type II gastric carcinoid tumors with somatostatin analogues. New England Journal of Medicine 343 551-554. (doi:10.1056/NEJM200008243430805)

Turner NC, Strauss SJ, Sarker D, Gillmore R, Kirkwood A, Hackshaw A, Papadopoulou A, Bell J, Kayani I, Toumpanakis C et al. 2010 Chemotherapy with 5-fluorouracil, cisplatin and streptozocin for neuroendocrine tumours. British Journal of Cancer 102 1106-1112. (doi:10.1038/sj.bjc.6605618)

Villaume K, Blanc M, Gouysse G, Walter T, Couderc C, Nejjari M, Vercherat C, Cordier-Bussat M, Roche C \& Scoazec JY 2010 VEGF secretion by neuroendocrine tumor cells is inhibited by octreotide and by inhibitors of the PI3K/AKT/mTOR pathway. Neuroendocrinology 91 268-278. (doi:10.1159/000289569)

Virgolini I, Britton K, Buscombe J, Moncayo R, Paganelli G \& Riva P 2002 In- and Y-DOTA-lanreotide: results and implications of the MAURITIUS trial. Seminars in Nuclear Medicine 32 148-155. (doi:10.1053/snuc.2002.31565)

Watanabe R, Wei L \& Huang J 2011 mTOR signaling, function, novel inhibitors, and therapeutic targets. Journal of Nuclear Medicine 52 497-500.

von Wichert G, Jehle PM, Hoeflich A, Koschnick S, Dralle H, Wolf E, Wiedenmann B, Boehm BO, Adler G \& Seufferlein T 2000 Insulin-like growth factor-I is an autocrine regulator of chromogranin A secretion and growth in human neuroendocrine tumor cells. Cancer Research 60 4573-4581.

Wulbrand U, Remmert G, Zöfel P, Wied M, Arnold R \& Fehmann HC 2000 mRNA expression patterns of insulin-like growth factor system components in human neuroendocrine tumours. European Journal of Clinical Investigation 30 729-739. (doi:10.1046/j.1365-2362.2000.00700.x)

Yakes FM, Chen J, Tan J, Yamaguchi K, Shi Y, Yu P, Qian F, Chu F, Bentzien F, Cancilla B et al. 2011 Cabozantinib (XL184), a novel MET and VEGFR2 inhibitor, simultaneously suppresses metastasis, angiogenesis, and tumor growth. Molecular Cancer Therapeutics 10 2298-2308. (doi:10.1158/1535-7163.MCT-11-0264)

Yao JC, Hassan M, Phan A, Dagohoy C, Leary C, Mares JE, Abdalla EK, Fleming JB, Vauthey J-N, Rashid A et al. $2008 a$ One hundred years after "carcinoid": epidemiology of and prognostic factors for neuroendocrine tumors in 35,825 cases in the United States. Journal of Clinical Oncology 26 3063-3072. (doi:10.1200/JCO.2007.15.4377)

Yao JC, Phan A, Hoff PM, Chen HX, Charnsangavej C, Yeung SC, Hess K, Ng C, Abbruzzese JL \& Ajani JA $2008 b$ Targeting vascular endothelial growth factor in 
advanced carcinoid tumor: a random assignment phase II study of depot octreotide with bevacizumab and pegylated interferon $\alpha$-2b. Journal of Clinical Oncology $\mathbf{2 6}$ 1316-1323. (doi:10.1200/JCO.2007.13.6374)

Yao JC, Shah MH, Ito T, Bohas CL, Wolin EM, Van Cutsem E, Hobday TJ, Okusaka T, Capdevila J, de Vries EGE et al. 2011 Everolimus for advanced pancreatic neuroendocrine tumors. New England Journal of Medicine 364 514-523. (doi:10.1056/NEJMoa1009290)

Zatelli MC, Minoia M, Martini C, Tagliati F, Ambrosio MR, Schiavon M, Buratto M, Calabrese F, Gentilin E, Cavallesco G et al. 2010 Everolimus as a new potential antiproliferative agent in aggressive human bronchial carcinoids. Endocrine-Related Cancer 17 719-729. (doi:10.1677/ERC-10-0097)

Zhang J, Jia Z, Li Q, Wang L, Rashid A, Zhu Z, Evans DB, Vauthey JN, Xie K \& Yao JC 2007 Elevated expression of vascular endothelial growth factor correlates with increased angiogenesis and decreased progression-free survival among patients with low-grade neuroendocrine tumors. Cancer 109 1478-1486. (doi:10.1002/cncr.22554)

Zitzmann K, Rüden J, Brand S, Göke B, Lichtl J, Spöttl G \& Auernhammer CJ 2010 Compensatory activation of Akt in response to mTOR and Raf inhibitors - a rationale for dual-targeted therapy approaches in neuroendocrine tumor disease. Cancer Letters 295 100-109. (doi:10.1016/j.canlet.2010.02.018)

Received in final form 27 March 2012 Accepted 2 April 2012 Made available online as an Accepted Preprint 3 April 2012 